\title{
A Review of the Analysis and Characterisation of Polymeric Glass Fibre Sizings
}

\section{James Thomason, University of Strathclyde}

\begin{abstract}
Glass fibre reinforcements form the backbone of a composites industry. Possibly the most critical component involved in the manufacture of glass fibres and their composites is the fibre sizing. Yet because of the intense level of secrecy surrounding size formulations there are few who have more than a superficial understanding of sizings. Composite developers and researchers have a growing need for practical tools which can assist with the understanding of the nature and role of sizings on the glass fibres which reinforce their composites. This work reviews some of the most relevant articles from the widely dispersed literature around the analysis and characterisation of these polymeric sizings. The review covers the analysis and characterisation of the polymeric sizing layer on the glass fibre surface using high vacuum surface analysis techniques, thermal analysis, atomic force microscopy based techniques, surface energy analysis, infrared methods, and combined multiple analysis techniques. The conclusions highlight the fragmented nature of the knowledge base on sizings and the lack of reliable and reproducible reference materials on which to build real progress in the understanding of this critical technology.
\end{abstract}

Keywords: A. Glass fibres; B. Interface/interphase; B. Surface properties; X. Sizing 


\section{Introduction}

Due to of their highly attractive performance/price ratio, glass fibres currently account for the majority of fibre reinforcements used in the fibre reinforced polymer composites industry [1]. Despite their relatively low-tech image the production of glass fibre for reinforcement applications has evolved into a very complex technology with requirements that challenge the state of the art in materials science, research and development. Possibly the most critical component involved in the manufacture of glass-fibres and their composites is the fibre size [2-6] a thin surface coating of mainly polymeric materials applied to nearly all types of man-made fibres during their manufacture. Sizings are essential processing aids for both the fibre manufacturing process and the manufacture of polymer composites. Moreover, due to its initial location on the fibre surface, sizing is a critical component in the formation and properties of the fibre-polymer interphase [4-6]. Obtaining an optimised composite interphase in the final composite is known to be essential in achieving the required short-term and long-term mechanical performance from a composite.

Glass fibre manufacture (shown in Figure 1) involves molten glass flowing under gravity through a platinum/rhodium alloy [7] bushings which contain a geometric array from 200 to as many as 8000 tipped orifices. Bushing plates are heated electrically, and their temperature is precisely controlled to maintain a constant glass viscosity. The molten glass drops from the bushing tips and is rapidly attenuated into fine fibres and sprayed with a fine mist of water below the bushing. Within milliseconds of forming 
and cooling, the glass fibres are coated with a sizing - commonly by contacting an applicator roll carrying a layer of an aqueous mixture of silane coupling agents, emulsified polymer film formers, lubricants and other additives [2,3]. The fibres are then brought together in a strand and pass on to the secondary processing stage, usually high speed winding or chopping. In terms of processability during chopping or winding, the sizing must perform certain functions within a fraction of a second after it has been applied. After drying ( 2 minutes to 1 day, depending upon the type of product) the sizing must provide a new set of properties to optimize composite processing and performance. Most commercially used sizings are aqueous chemical systems containing $0.05-10 \%$ solids which generally consist of a number of multi-purpose components. There will be a polymeric film former which, when dried, holds the filaments together in a strand and protects the filaments from damage through fibre-fibre contact and fibreprocess contacts. Film formers are chosen to be as closely compatible to the intended polymer matrix as possible and still fulfill all the other requirements of a sizing. Commonly used film formers include polyvinyl acetates, polyurethanes, polyolefins, polyesters, epoxies and modified epoxies [2,3]. Emulsion/dispersion technology allows many of these high molecular weight and water insoluble materials to be applied to glass fibre surfaces. Sizing will nearly always contain an organofunctional silane commonly referred to as a coupling agent. These multifunctional molecules have the ability to polymerise to form a polysiloxane structure which may also be chemically reacted with the glass fibre surface [2-7]. Despite the wide range of silanes available Thomason has shown that the glass fibre industry uses only three silanes for the vast majority of their sizings. These are aminopropyltriethoxysilane (APTES), methacryloxypropyltrimethoxysilane (MoPTMS), and glycidoxypropyltriethoxysilane [2,3]. Sizings may also contain cationic or nonionic lubricants to reduce fibre-fibre 
abrasion. There may also be a number of other additives, such as anti-static agents, emulsifiers, chopping aids, wetting agents, and antioxidants [3].

Whether for reverse engineering or to develop fundamental understanding of interphase and composite performance, the analysis of an unknown sizing which has been applied on, and dried to, a glass fibre bundle presents many challenges. The ratio of sizing to glass is very low which means that signal to noise ratios with many analytical techniques may be very poor and in many cases the signal from the sizing may be swamped by the effects of the glass. This can be further compounded by the fact that the sizing is rarely distributed uniformly through the sample at many scales $[5,8]$. In the typical commercial continuous glass fibre packages sizing migration during drying is known to lead to sizing concentration differences through the package [3]. At the fibre bundle level, wicking effects during drying may also lead to sizing being concentrated close to the fibre-fibre contact points. At the individual fibre level, the ratio of the sizing emulsion particle size to the fibre diameter, and thermodynamically driven preferential adsorption of individual sizing components, may lead to variation in coating uniformity. Furthermore, removal of single or groups of fibres from a fibre roving or chopped bundle may involve tearing of the sizing film which can also result in artificial sizing non-uniformity on the selected sample. Considering the conditions described above it is not surprising to find that the distribution of the applied sizing layer, comprising only $0.2-2 \%$ of the glass fibre product weight, is often non-uniformly distrubuted on the fibre surface, as illustrated in Figure 2. However, it is already well recognised that optimization of the sizing layer is essential to the production of successful reinforcement and composite products. Without the appropriate tools to investigate and quantify the sizing on fibres, one can never hope to be able to fully control its 
performance. For a fundamental approach to composite reinforcement products and for improved product quality control, it is essential to develop small-scale, short-term methods to analyze these polymeric sizing layers, and predict and control their influence on processability and composite performance. This requires the ability to characterize the nature of the sizing at both the nanometer level, where the sizing components interact with the glass surface, and at the micron level where the sizing may be chemically heterogeneous and physically non-uniformly distributed.

Despite the critical need of the composite industry to fully understand and control all aspects of the materials it uses, commercial glass fibres are often supplied with only two sizing related details. The first is an indication of the chemical compatibility of the sizing with a general class of matrix polymer, e.g. epoxy compatible or polyamide compatible. The second is normally a value for the loss on ignition (LOI), which gives a measurement of the amount of organic sizing present on the glass fibre product. LOI is determined by the weight loss of a sample after heat treatment at elevated temperature (in the $500-600^{\circ} \mathrm{C}$ range) [9]. It is worth noting that in silane rich, and silane only, sizing formulations only a small fraction of the original silane molecule is organic and available on the fibre surface for high temperature removal [3]. This lack of information on the physical and chemical nature of the sizing on a glass fibre product is an issue for many users of glass fibres, be they interested in quality control for manufacturing or the fundamentals of the fibre-matrix interphase.

From the above discussion it should be clear that those involved with polymer composites research and development have a need for practical tools which can assist with the understanding of the nature and role of sizings on the glass fibres which 
reinforce their composites. Although there has been a lack of systematic research and development published on analysis and characterization of sizings, it is an area which has received attention from a number of researchers in many different fields.

Consequently, there is some information available, although it is quite widely dispersed through the technical literature and there has not previously been a journal review focussed on this issue. Given the importance of sizings to the continuing success and growth of the composites industry this work reviews some of the most relevant articles from the widely dispersed literature which is openly available around the analysis and characterisation glass fibre sizings. The review is divided into sections covering the main types of analytical methods employed. These include high vacuum surface analysis techniques, thermal analysis, atomic force microscopy based techniques, surface energy analysis, infrared methods, and combined multiple analysis techniques. The influence of sizing on the properties of the fibre-matrix interphase and the performance of glass fibre reinforced composites has been discussed in a separate review article [7].

\section{High Vacuum Surface Analysis Techniques}

The use of high vacuum surface analysis techniques such as X-ray photoelectron spectroscopy (XPS) and secondary ion mass spectroscopy (SIMS) in the study of the surface layers of glass and glass fibres has been extensively reported. The high levels of surface sensitivity offered by such techniques are attractive in tackling some of the challenges listed above. However, there is an extensive list of potential pitfalls awaiting the unwary when assessing the relevance of the conclusions drawn from these types of analysis. The high levels of sensitivity of such techniques results in the detection of contaminants present in minute quantities. This poses serious questions 
about the application of such techniques to industrially sourced fibre samples with an unknown detailed history. The quantifiable values of the data from techniques such as XPS, although initially attractive, are dependent on the appropriate standards being used, and may also be highly dependent on hidden assumptions in the instrument manufacturers software which may not be immediately applicable to fibrous materials. Many users often choose to bypass the difficult issue of the extraneous Carbon signal which is present in nearly all XPS analyses. Furthermore, because of the time and expense involved in high power surface analysis, very few investigations contain statistical analysis of their surface analysis data. Information on reproducibility, repeatability and representativeness of the sampled area are often absent and in many cases conclusions are drawn from single measurements on a tiny surface area of a single specimen - a situation which would be considered unacceptable for say mechanical testing of the tensile or impact strength of a polymer composite. The inexperienced or infrequent user of surface analysis may also not be aware of the issues arising from the orientation, curvature and irregularity of the surface of fibre bundles with these techniques which were often initially developed for analysis of flat surfaces. Consequently, the level of analysis of the data obtained from such techniques should realistically reflect the level of effort expended in appropriate sample preparation.

Mellott et al. have published [10] a very useful report on appropriate methods of glass surface preparation by polishing, fibre-drawing, melt-casting and chemical etching evaluated with XPS and Atomic Force Microscopy (AFM) for a variety of aluminosilicate glasses. It was shown that polishing can alter the surface composition of these multicomponent glasses, and that post-etching of the polished surface to 
expose the bulk composition is plagued by preferential leaching, contamination and roughening. A highly significant conclusion was that there is a strong dependence of these surface compositional modifications upon the specific glass; even within specific glass systems, the polishing and etching procedure must be modified to yield a surface with the bulk composition.

Fagerholm et al. [11] investigated the adsorption of a non-ionic surfactant, frequently used in sizing formulations, from aqueous solutions onto industrial E-glass fibres. Unsized chopped E-glass fibres were dip coated in surfactant solution with a range of concentrations. After drying, the surface properties of these samples were characterized using XPS, electrokinetic analysis (EKA) and wetting characteristics. All three techniques indicate substantial changes in the interaction between glass fibres and water as a consequence of surfactant adsorption, although it seemed that only a fraction of the total fibre surface was covered by the surfactant. The wettability of the fibres provided indirect information concerning the surface coverage and polarity of the fibres. The XPS results were shown to provide semi-quantitative information about the amount of surfactant adsorbed on the fibre surface, and correlated well with the wetting properties. The same authors reported [12] on this subject again with fibres conditioned in surfactant solutions of different $\mathrm{pH}$. Following acidic $\mathrm{pH}$ treatment, the XPS Si/Al ratio of the fibre surface increased due to aluminium ions being leached out of the glass structure. The $\mathrm{Si} / \mathrm{Al}$ ratio was unchanged after treatment in moderately alkaline solutions. The effect of the surface conditioning in solutions of different $\mathrm{pH}$ seemed to be greatest for the acidic solutions giving rise to an increased adsorption of the surfactant on the glass-fibre surface. In another paper from the same group, Lassas et al. [13] used a similar range of 
techniques to investigate the modification of E-glass fibre surfaces with polyacrylic acid (PAA) polymers, another class of chemicals found in some commercial sizing formulations. The same E-glass fibres were dip coated with various concentrations of aqueous PAA solution. PAA can exchange protons with the ions present in the glass surface and hydrolyzed metal cations may form salt complexes with the dissociated PAA. The cation exchange property of glass fibre was studied using direct current plasma (DCP), which showed that both calcium and aluminium ions were extracted by low concentration PAA solutions. XPS studies showed that the amount of PAA on the glass surface increased with increased acid concentration. A broadened and shifted XPS carbon peak $(\mathrm{O}-\mathrm{C}=\mathrm{O})$ was interpreted as indicating the formation of salt complexes between the PAA and metal ions on the glass surface. Fagerholm et al. [14] also studied the modification of the same chopped E-glass fibres by long-chain alcohol adsorption using a combination of XPS, Diffuse Reflectance Fourier Transform Infra-red (DRIFT), and contact angle CA analysis. The authors pointed out that such alcohols are known to bond to silica surfaces but less information is available for glass surfaces but that they may offer a cheaper alternative to the use of silane coupling agents. Various long chain alcohols were reacted at $130^{\circ} \mathrm{C}$ with unsized E-glass fibres. It was reported that these long chain alcohols adsorbed strongly on E-glass surfaces. Contact angle analysis indicated incomplete coverage of the glass surface. The adsorbed alcohol was found to be resistant to removal by organic solvents, produced a major change in surface composition and hydrophobicity, but was apparently not present at complete monolayer coverage. No further conclusion was drawn about the suitability for replacing silanes. Dwight et al. [15] studied the role of Lewis acid-base interactions at the fibre-matrix interface in glass reinforced polyester and epoxy composites. The E-glass fibres were 
sized with three silane coupling agents: APTES, MoPTMS, and GPTMS alone and with aqueous solutions of $0.5 \%$ wt of silane coupling agent and PVA film former. Unidirectional composites were manufactured with both polyester and epoxy matrices. Silane adsorption mechanisms and composites properties were investigated using a combination of XPS, scanning electron microscopy (SEM), and flow microcalorimetry. The authors concluded that the unsized basic glass fibres bonded to the acidic epoxy matrix but not the polyester. However, silane coupling agents were adsorbed in patches and provided acidic sites for interaction with the basic polyester functional groups, as well as stronger basic sites to enhance interaction with the acidic epoxy sites. Norstrom et al. [16] reported the use of XPS and EKA to characterize the surface of silane only sized E-glass fibres. The glass fibres were treated for $3 \mathrm{~min}$ in solutions of $0.05-0.5 \%(\mathrm{wt} / \mathrm{wt})$ of various silane coupling agents. After drying the glass fibres were again immersed in deionized water for $1 \mathrm{~min}$ to remove the excess silane from the surface. XPS provided information on the amount adsorbed and indicated that substantial rearrangement in the surface film structure occurred as a function of the silane concentration. The aminosilanes produced a strong positive charge on the glass fibres, while the non-ionic silanes were only partly condensed, giving rise to a substantial enhancement of the negative charge. The conductivity measurements indicated that the silane films were present as a loose patchy silane network on the surface of the E-glass fibres.

The combination of systematic aqueous extraction combined with surface analysis techniques such as XPS and SIMS may also be applied to sized fibre samples following protocols developed to give comparative detailed information of silane interaction with different glass fibre formulations. Liu et al. $[17,18]$ used systematic 
aqueous extraction at increasing temperatures to study the hydrolytic stability of the silane layer deposited on E-glass. XPS analysis of samples after different extraction treatments confirmed the presence of components of differing hydrolytic stability in the aminosilane sizing layer. These were associated with physisorbed, loosely chemisorbed, and strongly chemisorbed components. Shallenberger et al. [19] have also used these extraction techniques to investigate the competitive adsorption of silanes APTES, mercaptopropyltrimethoxysilane (MPTMS), aminopropylsulfanylpropyltrimethoxysilane (APSPTMS) and lubricants onto E-glass surfaces. In an XPS study of silanes on glass Choudhury and Jones [20] adsorbed MPTMS onto model surfaces from 3\% aqueous solution. Silica glass, acid-treated Eglass and E-glass were employed to establish if the Si $2 p$ core has electrons of significantly different binding energy in the siloxane structures associated with a hydrolysed trialkoxy monoalkyl silane and a silicate surface which enables differentiation to be achieved. It was shown that it is practical for silica surfaces including E-glass denuded of the network modifiers but not for E-glass surfaces. Wang and Jones [21] used TOF-SIMS and XPS to study the interaction of APTES silanized E-glass plates with the epoxy resin diglycidyl ether of bisphenol S (DGEBS). In the TOF-SIMS spectra, in addition to a series of ion fragments readily assigned to the parent DGEBS epoxy resin, some new ion fragments attributable to the reaction product of DGEBS with the polymeric APTES precoating were observed. In the XPS spectra a mixed coating of APTES and DGEBS was demonstrated by the presence of intense N1s and S2p peaks. They stated that the APTES deposit is strongly bound to the E-glass plate surface and that direct confirmation of the formation of chemical bonds at the E-glass silane- resin interface was obtained. 
Wang, Jones and Denison [22-24] also published a series of papers reporting a study of the interaction between APTES and E-glass surface using TOF-SIMS and XPS. The TOF-SIMS results were interpreted by assigning a series of mass peaks to the structural unit of the poly(aminosiloxane). The highest mass fragment was obtained from the coating exposed by extraction with warm water (697 AMU). The largest molecular fragments would appear to have degrees of polymerization of six with differing numbers of silanol groups. On further extraction with hot water the fragment size decreased. It was postulated that the network chain length of the threedimensional polymer decreased as the interface was approached. Angle-resolved XPS revealed the formation of an APTES coating with a thickness of about $6 \mathrm{~nm}$, which consisted of three polysiloxane components of differing molecular structure on the glass surface. The authors also concluded that a most important observation was their confirmation that aluminium from the glass fibre surface is incorporated integrally into the aminosilane coating. Liu et al. $[25,26]$ used similar techniques to study differential adsorption from silane mixtures onto model E-glass fibre surfaces. Unsized E-glass fibres were washed with nitric acid for six days at room temperature to extract non-silicon elements, which otherwise interfere with the XPS analysis. These were immersed in the solutions of APTES, GPTMS and APTES/GPTMS (1:1) for $15 \mathrm{~min}$ each at room temperature. Silane solutions with concentrations $0.1 \%, 0.5 \%$ and $1.0 \%$ by weight were investigated. Using high resolution XPS it was found that APTES and GPTMS were equally adsorbed onto model E-glass surfaces from $0.1 \%$ APTES/GPTMS mixed silane solution. When the concentration of mixed silane increases to $0.5 \%$ and $1.0 \%$, more GPTMS than APTES was detected in the siloxane layer. 
Berg and Jones [27] investigated the role of sizing film formers, coupling agents and their blends on the formation of the interphase in glass fibre epoxy composites. The fibres used in this study were unsized E-glass fibre dip-coated with a variety of coatings based on APTES and epoxy resin sizing emulsions of low, medium and high molecular weights. A commercial epoxy sized fibre was also used as a control. XPS and SEM were used to estimate the thickness and uniformity of the sizing layer on these fibres. In an attempt to simulate possible properties of a sizing rich interphase region blends of two of the film former and matrix resin were produced. The addition of these film formers was shown to significantly change the modulus, strength and $\mathrm{Tg}$ of the matrix in some cases. The interfacial shear strength was determined using single fibre fragmentation testing. Results showed that all sized fibres exhibited a lower interfacial strength than the unsized fibres. However, due to the high level of scatter in the results, there were no real significant differences apparent between the various sized fibres.

Thomason and Dwight $[8,28]$ extended their insight into the use of XPS as a tool for the rapid characterization of sizings on commercial glass fibre products. XPS data were obtained from a wide range of commercial and experimental glass fibres using three different XPS instruments. By developing a protocol to plot ratios of appropriate atom concentrations, XPS analysis was shown to give new insights into the in-situ nature of the sizing layer on glass fibres. Analysis of different atom concentration ratios were used to estimate the surface coverage of the sizing on the glass fibres and to obtain information on the chemical composition of the sizing layer. Relationships between the XPS data and coated glass fibre parameters were clarified with the aid of a patchy overlayer model. In comparing data from three different XPS instruments 
excellent correlation was obtained after correcting for differences in spectrometer sensitivity factors. The same authors presented the full details of their patchy overlayer hypothesis and its application to the analysis of XPS data obtained on commercial glass fibres in a further paper [29]. XPS data obtained on four epoxycompatible and four polypropylene compatible E-glass fibre rovings were presented and discussed. The average sizing surface coverage levels obtained were shown to correlate to composite strength and the authors concluded that the unsized fibre regions may act as sites of higher flaw density or severity.

\section{Thermal Analysis}

Dynamic Mechanical Analysis (DMA) has been used extensively to characterize both sizings in-situ on fibres and also to probe the sizing rich interphase in composites. A number of authors have shown how glass fibre strands can be mounted for analysis in various DMA instruments [30-36]. Mechanical properties such as storage modulus, loss modulus, and loss factor $(\tan \delta)$ can be determined as a function of temperature and deformation. The loss modulus and $\tan \delta$ curves usually exhibit one or more well defined peaks in the $-100^{\circ} \mathrm{C}$ to $+50^{\circ} \mathrm{C}$ range which can be associated with the fibre sizing since glass fibres do not exhibit any transitions in this low temperature range. Miller [30] may well have been the first to demonstrate DMA investigation of glass fibre sizing using a DuPont 981 instrument. He investigated the DMA loss modulus peak position and height of two unspecified sizings on E-glass fibre strands. Results showed that the peak position and height could be affected by the sizing type, the strand and sizing drying conditions, the production facility and sample selection. Maier and Biehl [31] compared results on sized carbon and glass fibres obtained using a torsion pendulum and a DMA (unspecified but possibly a DuPont model from the 
picture of the clamps). They investigated the response of sizings based on polyvinylaceate, epoxy resin, and polyurethane modified epoxy. No details of the sizing application procedure or the use of silane coupling agents were noted. They stated that despite the low amounts of organic material coated on the fibres $(0.5 \%$ to $2.4 \% \mathrm{wt}$ ) the coating transition temperatures could be determined by both techniques. They suggest that their results indicate that this technique could be used for quality control of sizings on fibres.

Chua [32] used DMA to investigate $0.5 \%$ aqueous silane sizings onto 1100 tex Eglass fibre strands using a DuPont 982 instrument, sample mounting and deformation method were unspecified. It was notable in the results that only very broad peaks were demonstrated by the silane sized fibres. Eckstein [33] also examined silane sized glass fibre cloth in a DuPont 981 DMA at a constant clamp gap setting of only $3.4 \mathrm{~mm}$. Two different silanes were coated from aqueous solutions ranging in concentration from 0.01 to $2.5 \mathrm{wt} \%$ on to heat-cleaned woven glass cloth tape, $12.7 \mathrm{~mm}$ wide and $0.25 \mathrm{~mm}$ thick. Single and double peaks were observed in the DMA damping curves for both silane coated samples depending on the concentration of the coating solution used. The authors stated that DMA measurements may provide valuable information on the composition. Thomason [4,34] used a DuPont 982 DMA and Millers sample mounting method [30] to study a wide range of sizings on 2400 tex commercial glass fibre products. Transition temperatures from $-30^{\circ} \mathrm{C}$ up to $65^{\circ} \mathrm{C}$ were detected, indicating a range of different sizing compositions. The bulk of the sizing was removed from one sample by solvent extraction and the strands were then recoated with different concentration of epoxy resin solutions to create a range of samples with a controlled sizing layer thickness of a known material on the same glass fibres. DMA 
results showed that the detected transition temperature was inversely proportional to the thickness of the sizing layer. The loss modulus peak temperature for a $500 \mathrm{~nm}$ thick sizing layer was found to be $33^{\circ} \mathrm{C}$, which was $26^{\circ} \mathrm{C}$ above the bulk resin transition temperature of $7^{\circ} \mathrm{C}$. The transition temperature of the thinnest layer applied $(10 \mathrm{~nm})$ was a further $18^{\circ} \mathrm{C}$ higher at $51^{\circ} \mathrm{C}$. These results clearly indicate that care must be taken in interpreting these DMA sizing peaks on glass fibres and attention must be paid to the amount of sizing on the fibres.

Carlier et al. [35] have reported on the use of a Rheometrics RSA II instrument to obtain supported DMA results on a range of commercial glass fibre samples. They also concluded that the technique shows possibilities for characterization and quality control of sizings on glass fibres. Zinck and Gerard [36] also used a Rheometrics RSA II in a DMA study of three differently sized kinds of E-glass fibres from Vetrotex. The three fibre sizings considered were aqueous solution of an antistatic agent only, a $1 \mathrm{wt} \%$ aqueous solution of APTES, and an industrial sizing referred to as P122 by Vetrotex where the coupling agent included in the sizing formulation was also APTES. Other components such as lubricant and film-former were also included. No further details of the samples were given; however these samples appear to be the same as used by the authors in another study [37]. APTES LOI was $0.17 \%$ and the full sizing LOI was $0.77 \%$ wt. The tan $\delta$ results for the silane and fully sized fibres showed a number of features which were apparently sensitive to the different hydrolytic treatments which were performed on the fibres. These results were interpreted in terms of a hybrid structure of the silane-sizing surface network. 
Consequently, there is a sizable body of evidence that DMA methods can be used to detect thermal transitions in the sizings on glass fibres strands and these results have been shown to be sensitive to the physical and chemical nature of the sizing layer. However, care should be exercised in discussing these results in terms of "spectra" or "fingerprints" since the response obtained from DMA instruments can vary enormously with instrument type, sample dimensions, clamping arrangements and heating rate. Thomason $[4,38]$ has discussed the errors and artefacts that these types of variable can produce when using the early DuPont 98X series of instruments, and other DMA instruments may also have a range of similar issues.

Larson et al. [39] investigated the formation of a sizing rich interphase through the use of micro-dielectrometry (MDE) to study swelling and dissolution rates of glass fibre sizings in a vinyl ester matrix resin. Three model commercial glass fibre sizings, having varying levels of solubility in the resin, were based on film formers of soluble polyester, semi-soluble polyvinylacetate (PVA) and insoluble polyurethane. It was shown that two distinct types of interactions, the initial resin swelling of the sizing and the dissolution of the sizing into the resin, can be monitored MDE. Furthermore, an estimate of the times associated with swelling and dissolution of the sizing into the matrix resin could be made from micro-dielectric measurements. The authors concluded that their results showed that the styrene penetration of these sizing systems is only slightly dependent on the solubility of the sizing systems in the resin.

An important aspect of the performance of the organic materials used in sizings is their ability to withstand the high temperatures often used when processing high performance composites. Rudzinski et al. [40] reported on the thermal degradation 
behaviour of model E-glass fibre sizings and their constituents studied using TGAFTIR and Pyrolysis-GC/MS. Four different sizings were studied based on the typical formulations used for polyamide compatible glass fibre reinforcements. Details of the sizing formulations were given and components were used in industry-relevant concentrations producing fibres with a LOI of $0.5 \mathrm{wt} \%$. The authors noted the experimental difficulties in reproducibly detecting the thermally induced weight loss from sized glass fibres with such small amounts of organic sizing. Nevertheless, they showed that the peak weight loss of the sizing on the fibres surface could occur at as much as $100^{\circ} \mathrm{C}$ lower than that of cast films. Gao et al. [41] also investigated the thermal stability of silane only sizings on commercial glass fabrics using a combination of TGA, XPS and ToF SIMS. E-glass fabrics coated with either APTES or TG970 (an undefined silane containing amino functionality) were investigated. These authors also noted the high levels of noise-to-signal ratio in the TGA curves of samples with such low organic content. The results appeared to indicate that the TG790 sizing had a higher temperature stability compared to APTES. Ramos et al. [42] investigated the influence of stability of raw materials used in sizings for $\mathrm{E}$ and glass fibre manufacture. The raw materials studied were an alkalimidazoline lubricant and a polyvinyl acetate aqueous homopolymer dispersion used as a film former. They used differential scanning calorimetry (DSC) and FTIR to identify irregularities such as contamination, ageing, and loss of volatiles, which could affect the sized fibreglass performance. Rheological analysis also showed significant changes in these materials with storage at room temperature over thirty days.

Tanoglu et al. [43] reported on the properties of the polymeric interphase structure that remains at the fibre surface due to the glass fibre sizings in epoxy matrix 
composites. Epoxy compatible sized E-glass fibres were custom made for this work by Owens Corning. The sizing contained three components: DGEBA epoxy film former, triblock ethylene oxide and propylene oxide copolymer as surfactant, and GPTMS coupling agent. Using LOI and acetone extraction experiments it was determined that only $17.5 \%$ of the total $0.6 \% \mathrm{wt}$ sizing on these fibres was bound to the fibre and the other $82.5 \%$ was acetone extractable. NMR analysis of the extracted sizing showed that it consisted of film former and surfactant only. The material bound to the fibre surface contained silane and surfactant but no film former. Model sizing systems were then reacted in the absence of a glass fibre surface and also subjected to acetone extraction. The non-extractable component was added, reacted in epoxy resin, and taken as a model for the interphase material in a composite. DSC and DMA were then used to characterize the Tg and flexural modulus of the model materials. The results showed that the $\mathrm{Tg}$ of the model interphase containing $40 \%$ wt of the extracted sizing was reduced to about $-5^{\circ} \mathrm{C}$ from a bulk matrix value of $155^{\circ} \mathrm{C}$ (which approximates to a loss in $\operatorname{Tg}$ of $4^{\circ} \mathrm{C}$ per $1 \%$ wt sizing mixed with the matrix). The interphase flexural storage modulus at room temperature was about $50 \%$ of that of the bulk matrix.

Thomason et al. [44] used TGA to investigate the thermal stability of a large range of commercial glass fibre products, both chopped strands and rovings, from different suppliers. They noted that polypropylene (PP) compatible sizings were completely degraded when thermally conditioned between $200-250^{\circ} \mathrm{C}$. This sizing degradation was associated with a total loss of adhesion ability with PP. They also noted an associated TGA measured weight loss from aminosilane sized fibres in the same temperature range and suggested that, since aminosilane is the commonly used 
coupling agent in PP compatible sizings, the loss in reinforcement effect of the commercial fibres could be due to thermal degradation of the aminosilane functionality. In a similar vein Jenkins et al. reported a TGA study of thermal stability of epoxy compatible sizes on glass and basalt fibres [45] and also confirmed the degradation of aminosilane in the $200-300^{\circ} \mathrm{C}$ temperature range [46]

\section{Atomic Force Microscopy Based Techniques}

AFM has been applied to the study of glass fibre surfaces and sizings by a number of authors. Raedlein and Friscat [47] reviewed instrumental and sample preparation parameters in using AFM to study glasses and glass fibres. In an early study Achari et al. [48] carried out a topographic study of glass fibres by AFM. Uncoated glass fibres, fibres sized with four different silane only sizings, and those with two full sizings were supplied by Owens-Coming in the form of rovings. The LOI of the organosilane in the coating made of a coupling agent alone was $0.2 \%$, while in the case of the complete sizing, it was $0.4 \%$. The coupling agents were GPTMS, APTES, N-(2aminoethyl)-3-aminopropyltrimethoxysilane and a proprietary benzylamino-silane. The full sizings were based on APTES and GPTMS coupling agents, no further details of the full sizing compositions were given although from the text it appears that the sizing contained a lubricant as well as film former and coupling agent. The uncoated glass fibres showed a relatively smooth surface whereas fibres sized with a coupling agent alone had a non-uniform structure because areas all along the length of each fibre are torn off when it is separated from others in the glass roving. Fibres coated with a complete sizing had no torn-off areas. The whole topography was regular, bumps seldom protruded from the overall surface plane, and the roughness value was always lower than that of virgin fibres. Turrion et al. [49] combined AFM 
with fluorescence methods to investigate aminosilane sizings coated onto heat cleaned glass fibres. Various solvent treatments were used to modify the coated fibres. In this case the AFM images revealed that the coupling agent was deposited onto the fibres in the form of homogeneously distributed "islands". Furthermore, differences in the size of the silane islands were observed when the silanized fibres were subjected to the effect of different solvents. One of the many competing roles of glass fibre sizing is to improve the frictional performance of contacting fibre surfaces during processing operations such as spinning and weaving. Behary et al. [50] used an AFM to perform lateral force microscopy (LFM) for a friction force analysis of glass fibres sized with either a starch film former (fibre A) or an epoxy prepolymer (fibre E). It was found that friction force values measured between a scanning microtip and a fibre surface are smaller than those evaluated between two sliding glass fibres. Important variations of lateral force signals by the LFM revealed the chemical heterogeneity of the sized glass fibre A, while for fibre E, ploughing effects and variations of the friction coefficient from one fibre to another as well as a greater friction coefficient than fibre A were detected.

Gupta et al. [51] used AFM to compare the roughness of the surfaces of silica and Eglass fibres. They proposed that the roughness of the pristine melt-formed surface is controlled by the surface tension of the melt surface. On the other hand, the minimum observed roughness of the pristine fracture surfaces in the mirror regions is related to the intrinsic nanometre scale inhomogeneities in the structure of the glass. Munz et al. [52] reported on the use of scanning force microscopy (SFM) as a tool for the detection of local mechanical properties of the interphase of fibre reinforced polymers. Examples were shown of investigation of the interphase around single glass 
fibres with a rather thick polypropylene sizing embedded in epoxy resin. The authors stated that SFM measurements with displacement modulation were shown to give information about local interphase compliance. Mai et al. [53] also used AFM images to visualize the surface roughness of glass fibres with different sizings. The surface of unsized E-glass fibres was relatively smooth. A glass fibre sized with APTES showed rougher surfaces since the silane formed "islets". In conjunction with a polyurethane film former the APTES covered the fibre surface completely but the roughness increased due to the dispersed film former. The authors also used AFM in force modulation mode to visualize interphases of 1-3 $\mu \mathrm{m}$ thickness and gradients in different fibre-matrix combinations. The results were interpreted as revealing interphases with different mechanical behaviours compared with the bulk matrix. Kim and Hodzic [54] reviewed a number of techniques which have been successfully applied to nanoscale characterization of the thickness and properties of interphase in glass reinforced polymer matrix composites. They presented an overview of the properties and effective thickness of the interphase formed between glass fibres and polymer matrices. They stated that the gap between physico-chemical investigation and bulk material testing can be bridged by using techniques such as nanoindentation, nanoscratch tests, and AFM. They presented a range of results on differently sized glass fibres which showed that the effective interphase thickness can vary from as small as a few hundred $\mathrm{nm}$ to as large as $10 \mu \mathrm{m}$, depending on the sizing constituents, the coupling agent, and sample ageing conditions.

\section{Surface Energy Analysis}

The thermodynamics of fibre surfaces and interfaces is a subject of paramount importance to the fundamentals of composites. The need to understand and 
characterize the role of surface and interfacial energy of the component materials is found at many points through composite lifetime. Fibre formation itself is controlled by the surface tension of the molten glass, the pickup and wetting of glass fibres by the aqueous sizing mixture is driven by surface and interfacial energies, the redistribution of sizing through the fibre strands and the wound packages of glass before and during drying is controlled by wicking and surface thermodynamics. During subsequent composite production the efficient impregnation, wetout and wetthrough of sized glass fibres, strands and fabrics is critical to the eventual short and long term performance of the resultant composites. Consequently, the modification of surface and interfacial energies of glass fibres by sizings is a critical area of understanding. Sizings will often include a range of components designed to improve the wetting of the fibre by the composite resin consequently improving interfacial adhesion. Fibre sizing researchers have a pervasive need for quantitative information regarding the wettability of fibres and filaments. Wettability characteristics can be a critical determinant of both processing and end-use behaviour. In addition, changes in wettability are often used as an indication of the nature or degree of surface modification, either chemical or physical, of polymeric materials. General practice has been to use the equilibrium contact angle between a liquid and a solid surface as a measure of the wettability of the solid by that liquid. While this is readily feasible experimentally with flat solid surfaces, it becomes a more challenging when the curved surface of a 10-20 $\mu \mathrm{m}$ diameter glass filament is to be investigated. One of the most frequently employed methods with glass fibres is based on the using a Wilhelmy type microbalance to measure the wetting force of a liquid on a single fibre as proposed by Miller and Young [55]. Nishioka [56] used a wetting balance to investigate the interaction of organosilanes with glass fibres. Three monofunctional 
silanes were dip-coated multiple times onto heat cleaned E-glass fibre fabrics. The advancing and receding contact angles of different liquids on silane sized glass fibres were measured. The results indicated a gradual decrease in the polarity of the fibre surface with increasing levels of silane. A saturated surface resulted after ten coating treatments, yielding a surface whose hydrogen bond component to the work of adhesion against water was much lower than that obtained with conventional trifunctional silane treated fibre surfaces.

Wolff et al. [57] investigated the surface heterogeneity of sized glass fibres using CA analysis. The samples appear to be from the same group discussed in references 210 and 212 with two, silane only, sized fibres (APTES, GPTMS) and two samples with a full sizing based on these two coupling agents. Three parameters were used to analyse the results: places where filaments were extracted in the roving (inside or at the periphery), roughness and heterogeneity of the filaments surfaces (chemical heterogeneity). Statistical measurements of contact angles (of glycerol, tricresylphosphate and mineral oil) showed fibre to fibre heterogeneity within a roving strand of 800 filaments. The results were interpreted in terms of the chemical heterogeneity of the two full sizings. The sizing containing GPTMS had a homogeneous chemical composition whereas the sizing containing APTES was heterogeneous with low energy defects. Although the coupling agent was not the unique component of the sizing, its chemical nature played an important role in the chemical and physical state of the sizing on individual fibres on the inside or outside of the roving strand. Benito et al. [58] examined the surface energies of silane only sized heat cleaned glass fibres using the Wilhelmy method on single fibres. The fibres were heat cleaned at $450^{\circ} \mathrm{C}$ to remove the commercial sizing and then sized with a $1 \%$ 
APTES aqueous solution after different levels of acid surface activation. These fibres were also subjected to a 16 hour extraction in hot toluene before being examined using CA, FTIR and SEM analysis. The polar contribution to the total surface free energy of the silanized samples was found to be the highest for the fibres activated with boiling water whilst the dispersion component was similar for all of them. The degree of silanization was greatest for the acid activated samples and lowest for the water activated one. Barraza et al. [59] studied the wetting behaviour of boron free Eglass fibres both commercially sized and then coated by admicellar polymerization with a styrene-isoprene copolymer. Control fibres were heat cleaned at $500^{\circ} \mathrm{C}$. Advancing and receding contact angles on single fibres were measured at slow meniscus velocities $(2 \mu \mathrm{m} / \mathrm{s})$ using the Wilhelmy method with probe liquids of various characteristics. Distinctly different contact angles were reported from the dynamic wetting of fibres with different surface treatments. It was found that the heat cleaned fibres had a chemically homogeneous surface. However, sized fibres, especially those with coupling agents and the copolymer coating were chemically heterogeneous at the surface. Watson et al. [60] have also investigated the treatment of E-glass fibres with alternatives to the most commonly used silanes. Various authors have studied the wettability of various silane treated flat glass samples using contact angle methods and concluded that different silanes can dramatically change the wettability of glass surfaces $[61,62]$.

Mäder et al. [63] have published on the relationships between fibre sizings, interphase, and composite properties in glass fibre reinforced epoxy, polypropylene and polyamide. They applied a series of model sizings to glass fibres and utilised wicking testing on the fibre strands together with Zeta potential measurements, 
combined with micromechanical and macromechanical interphase tests. The authors concluded that contact angle and electrokinetic measurements permitted detection of differences in the surface treatment of glass fibres. An approximate correlation between the thermodynamic work of adhesion and the debonding shear strength was shown. Mäder [64] has also studied the use of different sizing treatments for control of interphase properties in glass fibre epoxy composites. Six differently sized glass fibres were produced on an in-house laboratory spinning device. These included, unsized glass fibres, and combinations of film former only, APTES only, and two sizings similar to proprietary commercial sizings containing APTES and film formers. The fibre surface energy was characterized by dynamic wetting and the adhesion to epoxy resin measured using SFPO. It was concluded that wetting tests can be used to study the fibre-matrix interaction.

Surface hydroxyl groups are thought to be the primary site on the surface of silica and glass fibres for the adsorption and reaction of water and organic sizing molecules. Zhuravlev [65] has extensively reviewed work on the adsorption of water and the role of hydroxyl groups on the surface of silica. For a completely hydroxylated surface, the average number of silanol groups was found to be $4.9 \mathrm{OH} / \mathrm{nm}^{2}$, which includes the number of free, isolated silanol groups and the vicinal $\mathrm{OH}$ groups which are hydrogen bonded $[65,66]$. It has also been shown that hydroxyl groups can be removed from a silica surface by treatment in the temperature range from 200 to $400-500^{\circ} \mathrm{C}$. In addition, Zhuravlev [66] has also investigated the rehydroxylation of silica surfaces. It was found that the complete rehydroxylation of silica surface could be achieved easily for those samples of silica which were subjected to heat treatment at temperature below $400^{\circ} \mathrm{C}$. After the treatment at a higher temperature, only partial rehydroxylation 
takes place. Since glass surfaces are also silica rich they have an analogously hydrated structure. Consequently, the reactivity of glass fibres is mostly determined by the hydroxyl groups present on the surface and it is important to distinguish the different types of surface silanols and their distribution. Romanenko et al. [67] have shown how NMR can be used to determine the full water and silanol group content of fibreglass. Nishioka and Schramke [68] compared the thermal desorption of water from E-glass fibres with powdered silica and observed more water per unit area adsorbed on E-glass fibres. They concluded that three molecular layers of adsorbed water were desorbed between $55^{\circ} \mathrm{C}$ to $200^{\circ} \mathrm{C}$ and silanol group condensation occurred at temperatures above $200^{\circ} \mathrm{C}$. Sub-surface water desorbed at $300^{\circ} \mathrm{C}$ at which temperature silica skeletal bonds are reported to be hydrolysable so that the surface composition of the fibres is highly variable. The quantity of water desorbed between $500^{\circ} \mathrm{C}$ and $800^{\circ} \mathrm{C}$ was suggested to result from the diffusion of bulk water from the inner structure. Pantano et al. [69] employed solid state 19F NMR to study (3,3,3trifluoropropyl) dimethylchlorosilane labelled silanol groups on E-glass fibre surfaces and determined the concentration of hydroxyl groups to be 0.50 to $1.44 \mathrm{OH} / \mathrm{nm}^{2}$ depending on the boron content of the glass. Carré, Lacarriere and Birch [70,71] have estimated the density of silanol groups at the surface of microscope slide glass as 2.5 $\mathrm{OH} / \mathrm{nm}^{2}$ using CA analysis of water under octane at the point of zero charge (pzc). Liu and Thomason [72] have used the same method to investigate the surface concentration of hydroxyl groups on the surface of an E-glass formulation used for glass fibre production. They determined the pzc for polished E-glass slides in a fully hydrolysed state and after dehydroxylation for one hour at $600^{\circ} \mathrm{C}$ under dry nitrogen gas. In both cases a maximum in contact angle was clearly observed at a $\mathrm{pH}$ of 3 . This value is in good agreement with other published values of the pzc of bare E-glass 
obtained by Electrokinetic Analysis [5,73]. Using the values of contact angle at the pzc they obtained values of 2.3 and $1.7 \mathrm{OH} / \mathrm{nm}^{2}$ for their E-glass surfaces before and after heat treatment at $600^{\circ} \mathrm{C}$.

Bellmann et al. [74] used EKA to characterize of the interaction between model sizings silanes and the surface of E-glass fibres. The model sizing was based on combinations of APTES, Aquad S50 cationic lubricant and an undefined epoxy resin. The results from EKA measurements were interpreted in terms of the competitive adsorption processes of different sizing components. In the sizing with only APTES and the lubricant it appeared that the fibre outer surface was dominated by the aliphatic tails of the lubricant. The influence of the epoxy film former was found to be less significant on the adsorption of the APTES coupling agent. Park and Kim $[75,76]$ studied the surface energies of glass fabrics sized with three different sizing systems for use in polyester matrix composites. Woven-glass fabric was desized by heat cleaning and then dipped coated in aqueous sizing mixture before drying to obtain an approximate sizing coating of $0.8 \mathrm{wt} \%$. The water based sizings all contained MoPTMS, glycerin and formic acid and either a polyvinyl alcohol, polyester, or epoxy resin film former. The surface energetics of the sized glass fibres were investigated in terms of contact angle measurements using the wicking method based on the Washburn equation. Different values of the dispersive and polar components of the surface free energy of these glass fibres were observed for the different sizing treatments. The experimental result of the total surface free energies showed the highest value in the epoxy-sized glass fibres. 
Inverse Gas Chromatography (IGC) is a sensitive technique for determining acidbase characteristics of solid materials. Two sized (APTES alone or APTES and maleic anhydride grafted polypropylene emulsion film former) and unsized E-glass fibres were investigated by Dutschk et al. [77] using IGC in the $30-100^{\circ} \mathrm{C}$ temperature range. Their conclusion was that the IGC method is too sensitive to give an unambiguous description of the complex character of heterogeneous glass fibre surfaces. However, IGC was used by Mills et al. [78] for the determination of the dispersive surface free energy and acid-base interactions of polyester or vinyl ester compatible E-glass fibres. The results were interpreted as showing the need for fibres intended for reinforcement of polyesters to be acidic to promote good adhesion since the matrix system is very basic. The glass fibres studied were found to have a dispersive surface energy component of $41.5 \mathrm{~mJ} / \mathrm{m}^{2}$ at $25^{\circ} \mathrm{C}$. This was stated to be somewhat higher than the $38 \mathrm{~mJ} / \mathrm{m}^{2}$ total surface energy of polyester-sized glass fibres by Park and Kim [75] but apparently consistent with IGC values being higher than CA analysis values. Bakaeva et al. [79] studied the surface heterogeneity of water-sized E-glass fibres using IGC. The surface of these E-glass fibres was found to be homogeneous for the adsorption of some solvents and heterogeneous for others. However, the authors stated that additional work is necessary to make IGC a reliable method for adsorption study of glass fibres.

\section{Infrared Methods}

Koenig and Ishida have reported extensively on the application of Infrared techniques such as DRIFT to the analysis of silanes and sizings coated onto E-glass plates and fibres [80-84]. Chiang et al. [85] studied the structure of APTES in aqueous solution and on heat cleaned E-glass fibres using FTIR spectroscopy. They concluded that 
APTES forms a multilayer on the E-glass fibre surfaces where the amino groups form intramolecular ring structures. They also suggested that the relative proportion of this structure of aminosilane probably determines the extent of interaction between this coupling agent and the resin matrix in composites. In a similar paper Naviroj et al. [86] also used FTIR to study the structure and adsorption characteristics of APTES on silica and E-glass fibres depending on $\mathrm{pH}$ in the range 2-12. Heat cleaned E-glass mats were dip-coated in the $\mathrm{pH}$-adjusted, $1 \%$ by weight APTES solutions. They reported that the structure of the aminosilane layer on the E-glass was highly dependent on the $\mathrm{pH}$ of the treating solution with a maximum adsorption occurring around the natural $\mathrm{pH} 10-11$. They also noted that the structure of aminosilane layer was affected by the presence of carbon dioxide when the $\mathrm{pH}$ range of the silane solution is between 6 and 12 .

Dibenedetto and Lex [87] evaluated the tensile strength of silane-only sized E-glass fibres spun from a 2040 filament bushing. The fibres were dip coated in a 5\% silane solution and then dried in a vacuum oven at $100^{\circ} \mathrm{C}$ for 30 minutes. This was followed by two consecutive extraction treatments of 1 hour in boiling water and 30 minutes under vacuum at $100^{\circ} \mathrm{C}$. FTIR spectroscopy was used to detect any remaining silane on the glass surface after the boiling water treatment. In comparison to the unsized fibres all of the silane coatings were found to improve the tensile strength of E-glass filaments, especially at large gauge lengths. Bikiaris et al. [88] reported on the use of silane coupling agent sizings in combination with modified polypropylene (PP) to influence the level of adhesion in glass fibre-PP composites. Commercial chopped Eglass fibres were heat cleaned and then coated with silane solutions (either APTMS or APTES) made in pure alcohol at $10 \%$ of the fibre weight. Unfortunately, these 
conditions are not really similar in any way to practical glass fibre production. These fibres were used to produce injection moulded GF-PP composites. The fibre coating was investigated using FTIR and SEM. Fibres coated with the APTMS were reported to give improved composite properties compared to those coated with the APTES. The authors interpreted their results only in terms of interfacial adhesion; they did not consider the potential effects of the fibre heat cleaning step on fibre-silane interaction, fibre strength or residual fibre length in their composites. In a more recent paper Suzuki and Ishida reported [89] on the effect of the miscibility between several silanes and PVAc film-forming polymer on the level of silanol condensation. Mixtures of a hydrolysed silane and PVAc were investigated with FTIR spectroscopy and size exclusion chromatography. The hydrogen bonding between the silanol groups of the silane and the carbonyl groups of PVAc and silanol condensation affected by PVAc were investigated. A correlation between the extent of hydrogen bonding and the miscibility between the organofunctionality of silane and PVAc was reported. The authors proposed that hydrolysed silanes form a micelle like phase in this sizing system, and the orientation of each silane molecule is controlled by the miscibility between the organofunctionality and PVAc which is expected to affect the silanol condensation and siloxane structure.

Kitagawa et al. [90] studied sizings on glass fibres using near-infrared (NIR) lightfibre optics spectroscopy. E-glass strands were sized with a mixture of an aminosilane coupling agent and a maleic anhydride-modified polypropylene binder. Two sized glass fibre samples with different molecular weights of MAPP were studied. The authors stated that their results showed how NIR could elucidate the formation of an amide bond between maleic anhydride-modified polypropylene binder and an 
aminosilane coupling agent on glass fibres. Le-Huy et al. [91] investigated the effect of silane concentration on the adsorption of sizings onto E-glass fibres. The adsorption of a poly(vinyl acetate-co-maleate) (PVAM) emulsion onto unsized water washed E-glass fibres was investigated from sizing formulations prepared by mixing the PVAM with varying concentrations of MoPTMS. The dip-coated fibres were dried at room temperature then rinsed in toluene and redried at $80^{\circ} \mathrm{C}$ before being characterized using LOI, DRIFT spectroscopy, XPS and SEM. Results showed that the PVAM film former did adsorb onto the fibres but did not entirely cover the surface or only formed very thin surface films. When the treated fibres were washed with toluene most of the coating was removed. LOI results combined with the DRIFT spectra indicated that the addition of the silane to the PVAM emulsion caused a decrease in the amount of size on the fibres but this did not coincide with a decrease in surface coverage. XPS results indicated surface coverage had increased with silane addition. The authors stated that these results showed that small increases in the silane concentration appeared to affect the amount of size adsorbed onto E-glass fibres.

\section{Combined Multiple Analysis Techniques}

The complexity of many sizing formulations often means that the maximum amount of information can only be obtained through the application of multiple analytical techniques to the characterization of sizing on glass fibres. Wesson et al. [92] used a combination of IGC, XPS and electrolytic thermodesorption analysis of water (ETA) to study the acid-base characteristics of silane-treated E-glass fibre surfaces. Packages of 200 filament strands were sized with either water, or water-methanol solutions of APTES, methyltrimethoxysilane (MTMS), or chloropropyltrimethoxysilane (ChPTMS). XPS analysis indicated that APTES and ChPTMS showed some 
preference for inverted surface orientation. Monolayer isotherms using Lewis acids and bases as probe adsorbates showed silane deposition to attenuate acid-base interaction between probe molecules and weak and medium strength sites on the substrate. Moisture thermodesorption analysis showed that the sorptive capacity for physically bound water was attenuated by all the silane treatments. Desorption polytherms using acidic and basic probes demonstrated that APTES imparted strongly acidic and basic chemisorptive characteristics to the glass surface. MTMS imparted acidic but not basic chemisorptive properties, while chlorosilane mitigated the acidbase properties of bare glass without imparting additional chemisorptive character. Chemisorptive properties imparted by silane deposition were not thermally stable, and disappeared upon increasing the system temperature to $300^{\circ} \mathrm{C}$.

Drumm and Ulicny [93] investigated the chemical nature of the sizings on fifteen different commercial glass fibre materials including random mats, woven mats and continuous rovings. Glass fibres with epoxy, polyester and vinylester compatibility were subjected to extraction in various solvents. The dried extracted residues were characterized by a variety of analytical techniques including FTIR, NMR and liquid chromatography. Sizing loadings were determined by solvent extraction and pyrolysis and ranged from 0.54 to 4.22 weight per cent with the heaviest amounts on random mats and the least amounts on rovings. The higher levels of organic coating are probably indicative of an addition binder application in a secondary processing step in the production of some mat products. All of the coatings analysed could be sorted into three classes which matched the matrix types recommended by the glass manufacturers. In each case, the coating consisted primarily of a mixture of two separate materials, designated as the "unreacted resin" and the "lubricant". Since the 
coupling agents used were not known and were generally present as only a small portion of the total coating mixtures, their identification was not possible.

Thomason reported [4] on a similar but much more extensive analysis of the sizings on fifteen commercial glass fibres rovings. Large volumes of glass fibre (up to $20 \mathrm{~kg}$ ) were extracted in acetone to obtain substantial amounts of sizing extract for further analysis. A wide range of analytical methods was used to investigate these coatings, both on the glass fibre surface and in the composite. These included FTIR spectroscopy and NMR for chemical analysis of the extracted sizing. XPS and SIMS for in-situ analysis of the as received and extracted fibre surfaces for their atomic and chemical nature and the sizing distribution on the fibre surface. DSC and DMA for the thermal transitions of the sizings and the influence of sizing on the properties of various epoxy resin matrices. Single fibre CA measurements with epoxy resin gave information on the influence of sizing on wetting behaviour and on the chemical heterogeneity of the sizing surface layer. The results indicated that the coupling agent on these commercial glass fibres had reacted with another component of the fibre coating. The effect of an interphase around the fibre, caused by incomplete dissolution of the coating in the matrix, was determined by DMA and the chemical nature of the interphase was investigated using scanning SIMS. Thomason and Knoester [94] also reported on the use of Confocal Scanning Optical Microscopy (CSOM) for the study of sizings on glass fibres both before and after processing into composites. They showed that inhomogeneity of the silane layer on silane-treated Eglass fibres could be imaged using CSOM in fluorescence mode. CSOM examination of glass fibre coated with vinyltrimethoxysilane coupling agent and uncoated glass fibres showed no fluorescence. However, glass fibre coated with APTES and two 
fully sized commercial glass fibres revealed fluorescence in the sizing layer. Interestingly, this fluorescent component of the sizing could still be detected at the fibre-matrix interface in cross sections of epoxy composites produced with these fibres. The distribution of this material around the composite interface also appeared to be inhomogeneous.

Feulliade et al. [95] also applied a wide range of techniques to the analysis of the sizing on two commercial glass fibre products for polyester reinforcement. Sizing extracts were examined using FTIR and Pyrolysis/GC/MS. XPS and SIMS was used to investigate the fibre surface before and after solvent extraction and capillarity methods were used to estimate contact angles and consequently dispersive and polar surface energy components of the sized glass fibres. This combination allowed the chemical nature of the sizing film formers and the antistatic agents to be identified. The same authors [96] also investigated the wetting characteristics and surface energies of sixteen sized glass fibre rovings with systematic changes in the sizing LOI; the type of antistatic agent; the application method of the antistatic agent, and the chemical nature of the film former. Some details of these sizings formulations were made available in the paper. A global analysis allowed the authors to conclude that the fibre stiffness, the glass mat permeability and the sizing solubility and swelling are the three most important factors determining the material flow during processing and the surface quality of the resultant SMC composites panels. Bledzki et al. [97] reported on the combined use of a number of analytical techniques in the insitu characterization of four different sizings on E-glass fibres. The capillary rise technique and inverse gas chromatography were used to determine the surface free energy. Zeta potential measurement was used to investigate the chemical properties of 
sized fibre surfaces. The sizing layer homogeneity was investigated by field-emission scanning electron microscopy (FE-SEM). Their results indicated that the surfaces of the glass fibres were completely covered by the sizings containing either a polyethylene film former or a cationic silane. However, the sizings containing APTES and either a polyurethane or an epoxy film former only partially covered the glass fibre surface.

Industrial sizing developers have been aware for some time that in sizing containing silanes and some lubricants that there may well be competition between these two molecules for absorption to specific sites on the glass fibre surface. In a recent study Beauvais et al. [98] investigated the impact of this competitive adsorption in the context of glass fibre forming process using silica surfaces with an APTES and a cationic double-chained surfactant (DOAIM) mixture. Surfactant adsorption on silica was studied as a function of the APTES concentration in organic water based sizing using FTIR spectroscopy and AFM. A reciprocating ball-on-plate tribometer was used to compare friction properties of silica in contact with the sizing mixture and in presence of each individual component. Surface forces were measured between silica and an AFM silicon nitride tip in the sizing and in the pure cationic surfactant solution. APTES on its own has no lubricant property and acted to suppress the cationic surfactant adsorption on silica. Polyethyleneimine (PEI)-based polyamides are an important class of chemical lubricant used in glass fibre sizings for their wellknown ability to enhance both the processing and performance of the fibres. Shallenberger et al. [19] used a combination of AFM, XPS, and static CA measurements to study the individual and combined adsorption behaviour of polyamides and two different silanes (APTES, APSPTMS) to both flat and fibre glass 
surfaces. Samples were analysed with and without solvent rinsing to separate the weakly bound (physisorbed) and more strongly bound (chemisorbed) species. AFM revealed that non-uniform coverage of the surface on virtually every treated glass sample with islands of polyamide $10-100 \mathrm{~nm}$ diameter and 3-7 nm thick over the surface. XPS analysis revealed that the polyamides adsorb to the glass surfaces via protonated amine species at the acidic $(\mathrm{OH})$ sites on the glass surface. In competitive co-adsorption studies it was found that amino-terminated silanes preferentially adsorb to the glass surface, relegating the polyamide to a physisorbed outer layer. When mercapto-terminated silanes were competitively co-adsorbed the polyamide was preferentially adsorbed even when present at a concentration of only one twentieth that of the silane.

Gorowara et al. [99] reported the molecular characterization of sizings on E-glass fibres sized using formulations available in the patent literature. These sizings consisted of various silane coupling agents (APTES, MoPTMS, GPTMS), film formers, and emulsifying surfactants in water and were applied from a $5.0 \%$ wt solids emulsion to E-glass fibres as produced in a manner consistent with commercial production. Fibres were analysed by loss on ignition before and after acetone extraction. The analyses of the extract solutions, with the fibre analysis, were used to determine the quantity and quality of the physically and chemically adsorbed layers using FTIR, HPLC size exclusion chromatography and XPS. After extraction, fibres sized only with a silane coupling agent solution exhibited a loss of only $2-15 \% \mathrm{wt}$ of the sizing whereas fibres sized with the multi-component sizings exhibited an extractability of $40-70 \%$ wt of the sizing. Nevertheless, it was found that all three species remain on the fibre after extraction and that both coupling agent and 
surfactant concentrations in the remaining coatings after extraction are higher than in the applied sizing. The extractable materials had molecular weights similar to the original sizing components, and therefore the authors concluded the transport properties of these components can be approximated using the pure component properties.

Wu et al. [5] studied the effects of different silane on the formation and structure of the sizing layer on glass fibre and the resultant effects on the performance of unidirectional glass-fibre-reinforced polyester composites. E-glass filaments were manufactured using an in-house single hole bushing and were coated using methacryloxy and amino silanes with one, two, and three silanols (mono-ol, diol, and triol) to two types of glass fibres with different bulk glass compositions in a range representative of commercial reinforcements. Fibre surface analyses by angulardependent XPS, EKA, and CA measurements were used to characterize the surface coatings. The microindentation technique was used to evaluate fibre-matrix interfacial adhesion. The authors stated that molecular modelling, ADXPS and EKA is a powerful combination for constructing detailed models of silane adsorption and bonding on glass fibre surfaces. Arora et al. [100] prepared a series of non-ionic and cationic aminohydroxysiloxanes deposited onto water sized E-glass fibres from toluene and THF solution. They used DRIFT and XPS for qualitative and quantitative determination of these silane only sizings. They concluded that the non-ionic aminohydroxysiloxanes bind more effectively to the glass surface than their cationic counterparts. Norstrom [101] studied the effect of silane concentration on the offline deposition of various silanes onto unsized chopped E-glass fibres. Aqueous solutions of three silanes were prepared in a range of concentrations. Both XPS and elemental 
analysis indicated that there were sizeable quantities of silane deposited on the surface of the E-glass fibres from the 1 and $2 \%$ silane solutions. The solution concentration, which gave the maximum amount deposited, was different for each silane tested. The same group has also reported [102] on the deposition of similar silanes from solution in ethanol onto the same fibres. They used DRIFT to show how ureido silane deposition from ethanol results in the silane bonding in the $-\mathrm{OCH}_{3}$ down orientation, with the ureido amine functions free for reaction with the polymer matrix.

Gao et al. [103] also used a combination of AFM with nanoindentation, FTIR, TGA and single fibre tensile testing to investigate the sizings on commercial glass fibres before and after various environmental conditioning regimes. They concluded that their results showed that sizing significantly affects both the number and size of flaws on the fibre surface through a healing mechanism. They also correlated fibre tensile strength and surface roughness with Griffith fracture predictions. Zhuang et al. [104] have reported on the application of PP compatible sizing using dual applicators. APTES coupling agent and a maleic anhydride grafted PP film (MAPP) former dispersion were applied to a 204 filaments yarn at separate stages and with different sequences. The surface properties of the sized glass fibres were studied using AFM, XPS, EKA and CA analysis. Furthermore, the transverse tensile strengths of unidirectional GF-PP composites were determined. It was shown that the dual applicator produced sized yarns with lower LOI and resulted in poor fibre-matrix adhesion strength. However, applying the silane at the first sizing stage with an increased roller speed produced sized yarns with lower LOI but performance quite close to single roller sizing applicator strand. 
Petersen reported analysis of the sizings on two commercial epoxy compatible glass fibre rovings from different manufacturers [105-7]. The soluble and non-soluble sizing fractions were obtained from acetone extraction and loss on ignition (LOI) experiments. The soluble sizing fraction was further analysed by FTIR and TGA-MS. Similarly, to previous researchers $[4,43,99]$ it was found that between $75-90 \%$ of the sizing was extractable, with one size exhibiting slightly higher acetone solubility. It was not possible to distinguish unambiguously between the fibres from different manufacturers with either FTIR or TGA-MS analysis. The observation of IR bands associated with DGEBA indicated that this epoxy resin is used as film former in both sizings. The FTIR analysis also indicated the presence of a polyethylene oxide lubricant and/or surfactant. Fibre samples were recoated with GPTMS after acetone extraction of the original sizing. The GPTMS modified fibres displayed significant higher interfacial adhesion in comparison to the fibres with the original sizing. The authors concluded from this that the original sizing was far from the optimal at facilitating strong adhesion between glass fibre and matrix. This can be seen as evidence of the challenge for size developers in that they must satisfy multiple processing demands on glass fibre products as well as maximising composite performance. Guo et al. analysed the sizings on six commercial glass fibre rovings which included two unsaturated polyester and epoxy compatible; two unsaturated polyester and polyurethane compatible; and two which were multi-compatible [108]. Similar to the results of other researchers it was found that a large fraction of the sizing, in the range from $66 \%$ to $82 \%$ of the total sizing, was acetone extractable. The acetone soluble sizing fractions were characterized using NMR. The presence of unsaturated polyester resin was identified in all six sizing extracts. XPS was used to analysis the residual sizing still bound to the glass fibre surface after acetone 
extraction. The results showed the presence of aminosilane coupling agents on the fibres.

McGravey carried out his $\mathrm{PhD}$ research project with goal of fully characterising a common glass fibre size as well as determining the effect of the size composition on its performance [109]. Batches of vinyl acetate based film-formers were created via emulsion polymerisation from a formulation supplied by Celanese. These filmformers were then incorporated into a working glass fibre size formulation. This contained silane, film former, lubricant, plasticizer and anti-static agent. Initial studies were undertaken to determine the location of the constituent species present in the size to produce an image of its structure. The film-former formulation was altered to produce a range of molecular weights and emulsion particle sizes. The performance of sizes produced from these film-formers was then investigated in the areas of clarity, film formation, wetting ability and strength. Analysis techniques employed included, Gel Permeation Chromatography, Photon Correlation Spectroscopy, Environmental Scanning Electron Microscopy (ESEM), ESEM-Energy Dispersive X-ray Analysis, Attenuated Total Reflection- FTIR Spectroscopy, UV-Visual Absorption Spectroscopy, Ion Beam Analysis, Dynamic Mechanical Analysis, Contact Angle Measurement and Wet-out Rate Analysis. Some of the main conclusions drawn from this wide-ranging, but little known, study are listed below: The coupling agent migrated to the glass-size interface during drying. A minor amount of lubricant migrated to the size-air interface during drying. The molecular weight of a filmformer did not alter the size's ability to form a continuous film if dried under suitable conditions. The molecular weight and particle size of a film-former did not alter a 
sizes fibre wetting ability due to the large amount of water in size formulations. An excess of coupling agent was present in the standard size formulation.

\section{Some Concluding Remarks}

The formulation and application of a polymeric glass fibre size to reinforcement fibres is a critical component to the cost-effective production of glass fibres and their processability into composite materials with optimized short and long term performance. However, due to the lack of reliable and verifiable information on the physical and chemical nature of sizings the generally available understanding of these complex chemical mixtures does not reflect the level of importance that they have in determining the success of any glass reinforced composite material in a specific application. It is well established the pace of technology development in any scientific field is directly proportional to the level of information sharing and to the number of well-informed researchers active in the field [110-112]. While rapid and expanding progress is made in developing areas of materials science where background information is more openly available, new size development continues to be carried out by a very small number of researchers in glass fibre manufacturers' laboratories. These very limited numbers of researchers operate in an isolated and restricted environment with little or no open exchange of information. It seems likely that the area is in near stagnation as many glass fibre products and their sizes are high up on the development S-curve, resulting in rapidly diminishing returns on effort. Indeed the glass fibre industry is on record as saying that the pace of product development across the glass fibre industry is moving at a slower pace than in the past [113]. It seems highly likely that this problem is a serious barrier to the innovation of improved GRP 
materials and is something that urgently needs to be addressed on an industry-wide level.

An interesting outcome of this review is that there is practically no information available in the open literature on what methods the manufacturers of glass fibres use to characterise their sizings and control the quality and consistency of their sized products. Because of the lack of any comprehensive or reliable database on the science and technology of glass fibre sizings and the lack of accepted analysis and characterisation techniques and standards for sizings the number of knowledgeable researchers outside of the glass fibre producers is extremely small. This is compounded by the secrecy surrounding sizing formulations and the unique conditions of sizing application during glass fibre manufacture [3] which require any serious research to be carried with access to a reasonably sized glass fibre bushing, which is very expensive to build and maintain. Consequently, it appears likely that the nature of all the interactions involved in size formulations, and the resulting interphase and composite performance are not at all fully understood, even by those with inside knowledge of size formulations.

The analytical methods used for characterisation of sizings, on fibres and in the bulk, covered in this review are summarised in Table 1 and 2 along with a brief description of the information which researchers have obtained and some of their comments on the issues encountered. It appears that the use of multiple analytical methods will maximise the amount and veracity of information obtaining from analysis of glass fibre sizings. In terms of analysing the composition of an unknown sizing on a glass fibre surface, where no knowledge of the sizing components is available, it appears 
that selective extraction using different solvents and conditions followed by analysis of the extracts offers the most productive route. Techniques such as NMR, FTIR and DSC have proven useful for the chemical analysis of such extracts. Surface analysis, especially using XPS, of the extracted fibres has proved useful in identifying any sizing components which are strongly bound to the fibre surface. In particular, this method can lead to information on the type of silanes present in the sizing. XPS has been shown to be capable of quantifying the level of the sizing coverage on the surface of commercial glass fibre products. Contact angle and surface energy analysis has also been shown to provide useful information on the heterogeneity of the surface of sized glass fibres. AFM has been used to probe the structure of glass fibre surface layers on the nanoscale. In particular, a number of authors have used AFM to demonstrate a poor distribution of the silane coupling agent, appearing as "islands" rather than a continuous layer, on the surface of sized glass fibres. In terms of characterising the properties of the sizing on a glass fibre surface the use of DMA to determine a transition temperature (or multiple transitions) of the sizing has been well reported. This appears to be one of the few methods which has been systematically investigated and verified by a number of research groups and could well be at least one candidate for a more detailed standardised approach to sizing characterisation. A number of papers are also available showing the use of TGA to characterise the thermal stability of the sizing on commercial glass fibres.

It is unfortunate that few, if any, researchers have published any work on a statistical analysis of repeatability and reproducibility of their analysis on glass fibre sizings. It seems likely that a large contributor to this problem is the secrecy surrounding sizing and the lack of any accepted standards by which to calibrate reproducibility and 
repeatability. The absence of such standards has seriously hampered the development of accepted sizing and sized glass fibres characterisation techniques and severely limits the ability of glass fibre users to check product quality and understand whether sizing issues contribute to any issues with their product. The composites community urgently needs the glass fibre industry to address this issue.

\section{References}

1. Composites World Sourcebook 2019, Part 1 Materials and Processes, the Fiber. https://www.compositesworld.com/articles/the-fiber

2. J.L. Thomason, Glass fibre sizing: A review of the scientific literature. Blurb Inc., (2012) ISBN 9780957381414.

3. J.L. Thomason, Glass fibre sizing: A review of size formulation patents. Blurb Inc. (2015) ISBN 9780957381438.

4. J.L. Thomason, The interface region in glass-fibre-reinforced epoxy resin composites: Part 3 Characterization of fibre surface coatings and the interphase, Composites 26 (1995) 487-498.

5. H.F. Wu, D.W. Dwight, N.T. Huff, Effects of silane coupling agents on the interphase and performance of glass-fibre-reinforced polymer composites, Compos. Sci. Tech. 57 (1997) 975-983.

6. J.L. Thomason, L.J. Adzima, Sizing up the interphase: an insider's guide to the science of sizing, Compos. Part A Appl. Sci. Manuf. 32 (2001) 313-321.

7. J.L. Thomason, Glass fibre sizing: A review, Compos. Part A Appl, Sci. Manuf. 127 (2019) Article 105619

8. J.L. Thomason, D. W. Dwight, The use of XPS for characterization of glass fibre coatings, Compos. Part A Appl, Sci. Manuf. 30 (1999) 1401-1413. 
9. ASTM D4963/D4963M-2011. Standard Test Method for Ignition Loss of Glass Fiber Strands and Fabrics

10. N.P. Mellott, S.L. Brantley, J.P. Hamilton, C.G. Pantano, Evaluation of surface preparation methods for glass, Surf. Interface Anal. 31 (2001) 362-368.

11. H.M. Fagerholm, C. Lindsjö, J.B. Rosenholm, K. Rökman, Physical characterization of E-glass fibres treated with alkylphenylpoly(oxyethylene)alcohol, Colloids Surf. 69 (1992) 79-86.

12. H.M. Fagerholm, C. Lindsjö, J.B. Rosenholm. Physical characterization of Eglass fibres treated with alkylphenylpoly(oxyethylene) alcohol - fibres conditioned in solutions of different pH, J. Mater. Sci. 30 (1995) 2420-2424.

13. A.C. Lassas, L.E. Fagerholm, B.G. Stelound, J.H. Nasman, Modification of Eglass fiber surfaces with polyacrylic acid polymers from an aqueous solution, Polym. Compos. 14 (1993) 1-6.

14. H.M. Fagerholm, J.B. Rosenholm, T.J. Horr, R.S.C. Smart, Modification of industrial E-glass fibres by long-chain alcohol adsorption, Colloids Surfaces A: Physicochem. Eng. Asp. 110 (1996) 11-22.

15. D.W. Dwight, F.M. Fowkes, D.A. Cole, M.J. Kulp, P.J. Sabat, L. Salvati, T.C. Huang, Acid-base interfaces in fibre-reinforced polymer composites, J. Adhes. Sci. Technol. 4 (1990) 619-632.

16. A.E.E. Norstrom, H.M. Fagerholm, J.B. Rosenholm. Surface characterization of silane treated industrial glass fibers, J. Adhes. Sci. Tech. 15 (2001) 665-679.

17. X.M. Liu, J.L. Thomason, F.R. Jones, XPS and AFM Study of interaction of organosilane and sizing with E-glass fibre surface, J. Adhes. 84 (2008) 322-337. 
18. X.M. Liu, J.L. Thomason, F.R. Jones, XPS and AFM study of the structure of hydrolysed aminosilane on E-glass surfaces, in: Silanes and Other Coupling Agents, K.L. Mittal (Ed.), vol. 5, Brill 2009.

19. J.R. Shallenberger, E. Metwalli, C.G. Pantano, F.N. Tuller, D.F. Fry, Adsorption of polyamides and polyamide-silane mixtures at glass surfaces, Surf. Interface Anal. $35(2003) 667-672$.

20. T. Choudhury, F.R. Jones, The interaction of silanes with amorphous silicon oxide surfaces, Int. J. Adhes. Adhes. 26 (2006) 79-87.

21. D. Wang, F. R. Jones, TOF SIMS and XPS study of the interaction of silanized E-glass with epoxy resin, J. Mater. Sci. 28 (1993) 1396-1408.

22. D. Wang, F.R. Jones, P. Denison, TOF SIMS and XPS study of the interaction of hydrolysed aminopropyltriethoxysilane with E-glass surfaces, J. Adhes. Sci. Tech. 6 (1992) 79-98.

23. D. Wang, F.R. Jones, P. Denison, Surface analytical study of the interaction between $\gamma$-amino propyl triethoxysilane and E-glass surface. Part I Time-of-flight secondary ion mass spectrometry, J. Mater. Sci. 27 (1992) 36-48.

24. D. Wang, F.R. Jones, Surface analytical study of the interaction between $\gamma$-amino propyl triethoxysilane and E-glass surface. Part II X-ray photoelectron spectroscopy, J. Mater. Sci. 28 (1993) 2481-2488.

25. X.M. Liu, J.L. Thomason, F.R. Jones, Differentiation of silane adsorption onto model E-glass surfaces from mixed solutions of amino and glycidyl silanes, in: Silanes and Other Coupling Agents, K.L. Mittal (Ed.), pp. 17-28, vol. 4, VSP, 2007. 26. F.R. Jones, X.M. Liu, J.L. Thomason, The differential adsorption of silanes from solution onto model E-glass surfaces using high-resolution XPS, in: Silanes and Other Coupling Agents, K.L. Mittal (Ed.), pp. 29-37, vol. 4, VSP, 2007. 
27. J. Berg, F.R. Jones, The role of sizing resins, coupling agents and their blends on the formation of the interphase in glass fibre composites, Compos. Part A Appl, Sci. Manuf. 29 (1998) 1261-1272.

28. J.L. Thomason, D. Dwight, The use of XPS for characterization of glass fibre sizings ', in Mittal, K.L. (ed) Silanes and other coupling agents, Volume 2, (VSP, Utrecht, 2000)

29. J.L. Thomason, D. Dwight, A model to assist XPS characterization of coatings on glass fibres, J. Adhes. Sci. Tech. 14 (2000) 745-764

30. D.G. Miller, The use of DMA for characterization of organic coatings on multiple glass fiber strands, American Laboratory, January (1982) 21-26.

31. G. Maier, K.H. Biehl, Thermomechanical measurements of fibre finish. Kunststoffe, 76 (1986) 282-284.

32. P.S. Chua, Dynamic mechanical analysis studies of the interphase, Polym. Compos. 8 (1987) 308-313.

33. Y. Eckstein, Role of silanes in adhesion-Part I. Dynamic mechanical properties of silane coatings on glass fibers, J. Adhes. Sci. Tech. 2 (1988) 339-348.

34. J.L. Thomason, A note on the investigation of the composite interphase by means of thermal analysis, Compos. Sci. Technol. 44 (1992) 87-90.

35. V. Carlier, M. Scalvons, R. Legras, Supported dynamic mechanical thermal analysis: an easy, powerful and very sensitive technique to assess thermal properties of polymer coating and even nanocoating, Polymer 42 (2001) 5327-5335.

36. P. Zinck, J.F. Gerard, On the hybrid character of glass fibres surface network, J. Mater. Sci. 40 (2005) 2759-2760 
37. P. Zinck, M.F. Pays, R. Rezakhanlou, J.F. Gerard, Mechanical characterization of glass fibres as an indirect analysis of the effect of surface treatment, J. Mater. Sci. 34 (1999) 2121-2133.

38. J.L. Thomason, Investigation of the composite interphase using Dynamic Mechanical Analysis: artifacts and reality, Polym. Compos. 11 (1990) 105-113.

39. B.K. Larson, L.T. Drzal, J. Van Antwerp, Swelling and dissolution rates of glass fiber sizings in matrix resin via micro-dielectrometry, Polym. Compos. 16 (1995) $415-420$.

40. S. Rudzinski, L. Häussler, C. Harnisch, E. Mäder, G. Heinrich, Glass fibre reinforced polyamide composites: Thermal behaviour of sizings, Compos. Part A Appl, Sci. Manuf. 42 (2011) 157-164

41. P. Gao, K.B. Su, Y. Ward, L.T. Weng, Effects of chemical composition and thermal stability of finishes on the compatibility between glass fiber and high melting temperature thermoplastics. Polym. Compos. 21 (2000) 312-321.

42. G. Ramos, A. Gomez, J. Guardiola, The influence of stability of raw materials used in sizings for E and AR fiberglass manufacture, Polym. Degrad. Stab. 51 (1996) $361-365$.

43. M. Tanoglu, S. Ziaee, S.H. McKnight, G.R. Palmese, J.W. Gillespie Jr., Investigation of properties of fibre/matrix interphase formed due to the glass fibre sizings, J. Mater. Sci. 36 (2001) 3041-3053.

44. J.L. Thomason, U. Nagel, L. Yang, D, Bryce, A study of the thermal degradation of glass fibre sizings at composite processing temperatures, Compos. Part A Appl, Sci. Manuf. 121 (2019) 56-63.

45. P.G. Jenkins, S. Riopedre-Méndez, E.R. Sáez, L. Yang, J.L. Thomason, Investigation of the strength of thermally conditioned basalt and E-glass fibres, 20th 
International Conference on Composite Materials, ICCM20, Copenhagen, Denmark, 19-24 July 2015.

46. P.G Jenkins, Investigation of the strength loss of heat treated glass fibre. $\mathrm{PhD}$ Thesis, University of Strathclyde 2016.

47. E. Rädlein, G.H. Frischat, Atomic force microscopy as a tool to correlate nanostructure to properties of glasses, J. Non-Cryst. Solids 222 (1997) 69-82. 48. A. El Achari, A. Ghenaim, V. Wolff, C. Caze, E. Carlier, Topographic study of glass fibers by atomic force microscopy, Text. Res. J. 66 (1996) 483-490.

49. S.G. Turrión, D. Olmos, J. González-Benito, Complementary characterization by fluorescence and AFM of polyaminosiloxane glass fibers coatings, Polym. Test. 24 (2005) 301-308.

50. N. Behary, C. Caze, A. Perwuelz, A. El Achari, Tribology of sized glass fibers. Part I: Friction analysis by lateral force microscopy and electronic microbalance technique, Text. Res. J. 70 (2000) 700-708.

51. P.K. Gupta, D. Inniss, C.R. Kurkjian, Q. Zhong, Nanoscale roughness of oxide glass surfaces, J. Non-Cryst. Solids 262 (2000) 200-206.

52. M. Munz, H. Sturm, , E. Schulz, G. Hinrichsen, The scanning force microscope as a tool for the detection of local mechanical properties within the interphase of fibre reinforced polymers, Compos. Part A Appl, Sci. Manuf. 29 (1998) 1251-1259.

53. K. Mai, E. Mäder, M. Mühle, Interphase characterization in composites with new non-destructive methods, Compos. Part A Appl, Sci. Manuf. 29 (1998) 1111-1119. 54. J.K. Kim, A. Hodzic, Nanoscale characterization of thickness and properties of interphase in polymer matrix composites, J. Adhes. 79 (2003) 383-414.

55. B. Miller, R.A. Young, Methodology for Studying the Wettability of Filaments, Text. Res. J. 45 (1975) 359-365. 
56. G.M. Nishioka, Interaction of organosilanes with glass fibres, J. Non-Cryst. Solids 120 (1990) 102-107.

57. V. Wolff, A. Perwuelz, A. El Achari, C. Caze, Determination of surface heterogeneity by contact angle measurements on glass fibres coated with different sizings, J. Mater. Sci. 34 (1999) 3821-3829.

58. J. Gonzalez-Benito, J. Baselga, A.J. Aznar, Microstructural and wettability study of surface pretreated glass fibres, J. Mater. Process. Technol. 92-93 (1999) 129-134. 59. H. J. Barraza, M.J. Hwa, K.Blakley, E.A. O'Rear, B.P. Grady, Wetting behavior of elastomer-modified glass fibers, Langmuir 17 (2001) 5288-5296.

60. H. Watson, A. Norström, Å. Torrkulla, J. Rosenholm, Aqueous amino silane modification of E-glass surfaces, J. Colloid Interf. Sci. 238 (2001) 136-146.

61. Y.C. Araujo, P.G. Toledo, V. Leon, H.Y. Gonzalez, Wettability of silane-treated glass slides as determined from X-ray photoelectron spectroscopy, J. Colloid Interf. Sci. 176 (1995) 485-490.

62. M. Wei, R.S. Bowman, J.L. Wilson, N.R. Morrow, Wetting properties and stability of silane-treated glass exposed to water, air, and oil, J. Colloid Interf. Sci. 157 (1993) 154-159.

63. E. Mäder, K. Grundke, H.J. Jacobasch, G. Wachinger, Surface, interphase and composite property relations in fibre-reinforced polymers, Composites 25 (1994) 739-744.

64. E. Mäder, Study of fibre surface treatments for control of interphase properties in composites, Compos. Sci. Tech. 57 (1997) 1077-1088.

65. L.T. Zhuravlev, Surface characterization of amorphous silica : a review of work from the former USSR, Colloids Surf. A 74 (1993) 71-90. 
66. L.T. Zhuravlev, Concentration of hydroxyl groups on the surface of amorphous silicas, Langmuir 3 (1987) 316-318.

67. K. V. Romanenko, O. B. Lapina, L. G. Simonova, J. Fraissard, 1H and 29SiMAS NMR characterization of silicate fiberglass supports, Phys. Chem. Chem. Phys. 5 (2003) 2686-2691.

68. G.M. Nishioka, J.A. Schramke, Desorption of water from glass fibres, in Molecular Characterization of Composite Interfaces, (Plenum, New York, 1983).

69. C.G. Pantano, R.A. Fry, K.T. Mueller, Effect of boron oxide on surface hydroxyl coverage of aluminoborosilicate glass fibres: a 19F solid state NMR study, Phys. Chem. Glasses 44 (2003) 64-68.

70. A. Carre, V. Lacarriere, W. Birch, Molecular interactions between DNA and an aminated glass substrate, J. Colloid Interf. Sci. 260 (2003) 49-55.

71. A. Carre, W. Birch, V. Lacarriere, Glass substrates modified with organosilanes for DNA immobilization, in Mittal, K.L. (ed) Silanes and other coupling agents, Volume 4, (VSP, Utrecht, 2007)

72. X.M. Liu, J.L. Thomason, F.R. Jones, The concentration of hydroxyl groups on glass surfaces and their effect on the structure of silane deposits, in: Silanes and Other Coupling Agents, K.L. Mittal (Ed.), vol. 5, Brill 2009.

73. E. Mäder, H.J. Jacobasch, K. Grundke, T. Gietzelt, Influence of an optimized interphase on the properties of polypropylene/glass fibre composites, Compos. Part A Appl. Sci. Manuf. 27 (1996) 907-912.

74. C. Bellmann, R. Plonka, A. Caspari, T. Luxbacher. Characterization of the interaction between silanes and solid surfaces by the streaming potential method. in Mittal, K.L. (ed) Silanes and other coupling agents, Volume 4, (VSP, Utrecht, 2007) 
75. S.J. Park, T.J. Kim, Studies on surface energetics of glass fabrics in an unsaturated polyester matrix system: Effect of sizing treatment on glass fabrics, J. Appl. Polym. Sci. 80 (2001) 1439-1445.

76. S.J. Park, T.J. Kim, J.R. Lee, S.K. Hong, Y.K. Kim, Influence of sizing agent on interfacial adhesion and mechanical properties of glass fiber/unsaturated polyester composites, Polym. Kor. 24 (2000) 326-332.

77. V. Dutschk, E. Mäder, V. Rudoy, Determination of polarity parameters for glass fibres by inverse gas chromatography: Some results and remarks, J. Adhes. Sci. Tech. 15 (2001) 1373-1389.

78. R.H. Mills, W.T.Y. Tze, D.J. Gardner, A. van Heiningen, Inverse gas chromatography for the determination of the dispersive surface free energy and acidbase interactions of a sheet molding compound. I. Matrix material and glass, J. Appl. Polym. Sci. 109 (2008) 3519-3524.

79. T.I. Bakaeva, C.G. Pantano, C.E. Loope, V.A. Bakaev, Heterogeneity of the glass fiber surface from inverse gas chromatography, J. Phys. Chem. B 104 (2000) 85188526.

80. R.T. Graf, J.L. Koenig, H. Ishida, Characterization of silane-treated glass fibers by diffuse reflectance fourier transforn spectrometry, Anal. Chem. 56 (1984) 773778.

81. S. Naviroj, S.R Culler, J.L Koenig, H. Ishida, Structure and adsorption characteristics of silane coupling agents on silica and E-glass fiber; dependence on pH, J. Colloid Interf. Sci. 97 (1984) 308-317.

82. S.R. Culler, H. Ishida, J.L. Koenig, The use of infrared methods to study polymer interfaces, Annu. Rev. Mater. Sci. 13 (1983) 363-386. 
83. H. Ishida, S. Naviroj, S.K. Tripathy, J.J. Fitzgerald, J.L. Koenig, The structure of an aminosilane coupling agent in aqueous solutions and partially cured solids, J. Polym. Sci. Pol. Phys. 20 (1982) 701-718.

84. H. Ishida, J.L. Koenig, Molecular organization of the coupling agent interphase of fiber-glass reinforced plastics, J. Polym. Sci. Pol. Phys. 17 (1979) 1807-1813. 85. C.H. Chiang, H. Ishida, J.L. Koenig, The structure of aminopropyltriethoxysilane on glass surfaces. J. Colloid Interf. Sci. 74 (1980) 396-404.

86. S. Naviroj, S.R. Culler, J.L. Koenig, H. Ishida, Structure and adsorption characteristics of silane coupling agents on silica and E-glass fibre; dependence on pH, J. Colloid Interf. Sci. 97 (1984) 308-317.

87. A.T.Dibenedetto, P.J. Lex, Evaluation of surface treatments for glass fibres in composite materials, Polym. Eng. Sci. 29 (1989) 543-555.

88. D. Bikiaris, P. Matzinos, A. Larena, V. Flaris, C. Panayiotou, Use of silane agents and poly(propylene-g-maleic anhydride) copolymer as adhesion promoters in glass fibre/polypropylene composites, J. Appl. Polym. Sci. 81 (2001) 701-709.

89. N. Suzuki, H. Ishida, Effect of the miscibility between a silane and a sizing agent on silanol condensation, J. Appl. Polym. Sci. 87 (2003) 589-598.

90. K. Kitagawa, S. Hayasaki, Y. Ozaki, In situ analysis of sizing agents on fibre reinforcements by near-infrared light-fibre optics spectroscopy. Vib. Spectrosc. 15 (1997) 43-51.

91. C.C. Le-Huy, L.G. Britcher, J.G. Matisons, The effect of silane concentration on the adsorption of poly(vinyl acetate-co-maleate) and methacryloxypropyltrimethoxysilane onto E-glass fibers, Silicon Chem. 1 (2002) 195-205. 92. S.P. Wesson, J. Jen, G.M. Nishioka, Acid-base characteristics of silane-treated E glass fiber surfaces, J. Adhes. Sci. Tech. 6 (1992) 151-169. 
93. C.A. Drumm, J.C. Ulicny, Analysis of coating on glass fiber reinforcements, Polym. Compos. 10 (1989) 44-51.

94. J.L. Thomason, A. Knoester, Application of confocal scanning optical microscopy to the study of fibre-reinforced polymer composites. J. Mater. Sci. Lett. 9 (1990) 258-262.

95. V. Feuillade, A. Bergeret, J.-C. Quantin, A. Crespy, Characterization of glass fibres used in automotive industry for SMC body panels, Compos. Part A Appl. Sci. Manuf. 37 (2006) 1536-1544.

96. V. Feuillade, A. Bergeret, J.-C. Quantin, A. Crespy, Relationships between the glass fibre sizing composition and the surface quality of sheet moulding compounds (SMC) body panels, Compos. Sci. Tech. 66 (2006) 115-127.

97. A.K. Bledzki, J. Lieser, G. Wacker, H. Frenzel, Characterization of the surfaces of treated glass fibres with different methods of investigation, Compos. Interfaces 5 (1997) 41-53.

98. M. Beauvais, L. Serreau, C. Heitz, E. Barthel, How do silanes affect the lubricating properties of cationic double chain surfactant on silica surfaces? J. Colloid Interf. Sci. 331 (2009) 178-184.

99. R.L. Gorowara, W.E. Kosik, S.H. McKnight, R.L. McCullough, Molecular characterization of glass fiber surface coatings for thermosetting polymer matrix/glass fiber composites, Compos. Part A Appl. Sci. Manuf. 32 (2001) 323-329. 100. P.S. Arora, J.G. Matisons, A. Provatas, R.C.Smart, Aminohydroxysiloxanes on E-glass fibres, Langmuir 11 (1995) 2009-2017.

101. A. Norström, H. Watson, B. Engström, J.B. Rosenholm, Treatment of E-glass fibres with acid, base and silanes, Colloids Surf. A 194 (2001) 143-157. 
102. H. Watson, P.J. Mikkola, J.G. Matisons, J.B. Rosenholm, Deposition characteristics of ureido silane ethanol solutions onto E-glass fibres, Colloids Surf. A $161(2000)$ 183-192.

103. S.L. Gao, E. Mäder, A. Abdkader, P. Offermann, Sizings on alkali-resistant glass fibres: Environmental effects on mechanical properties. Langmuir 19 (2003) 2496-2506.

104. R.C. Zhuang, T. Burghardt, R. Plonka, J.W. Liu, E. Mäder,. Affecting glass fibre surfaces and composite properties by two stage sizing application, Express Polym. Lett. 4 (2010) 798-808.

105. H.N. Petersen, Y. Kusano, P. Brøndsted, K. Almdal, Preliminary characterization of glass fibre sizing, Proceedings of the Risø International Symposium on Materials Science 34 (2013) 333-340.

106. H.N. Petersen, Y. Kusano, P. Brøndsted, K. Almdal, The influence of removing sizing on strength and stiffness of conventional and high modulus E-glass fibres, IOP Conf. Ser. Mater. Sci. Eng. 139 (2016) 012040.

107. H.N. Petersen, Investigation of sizing - from glass fibre surface to composite interface, PhD Thesis, Technical University of Denmark (2017)

108. X. Guo, Y. Lu, Y. Sun, J. Wang, H. Li, C. Yang, Effect of sizing on interfacial adhesion property of glass fibre-reinforced polyurethane composites, J. Reinf. Plast. Comp. 37 (2018) 321-330.

109. M.P. McGravey, An investigation into the structure and performance of a glass fibre size, PhD thesis, Durham University 2008.

110. W.B. Shockley, page 29 in Secrecy and Science, United States Government Pronting Office, Washington (1959) 
111. T. Takalo, V.Kanniainen, Do patents slow down technological progress?: Real options in research, patenting, and market introduction, Int J Ind Organ $2000 ; 18 ; 1105-1127$.

112. J.A. Evans, Industry collaboration, scientific sharing, and the dissemination of knowledge, Soc Stud Sci 2010;40:757-791.

113. P. Mapleston, Reinforcing options for compounders, Compounding World 2018 October page 80 


\section{Figures}

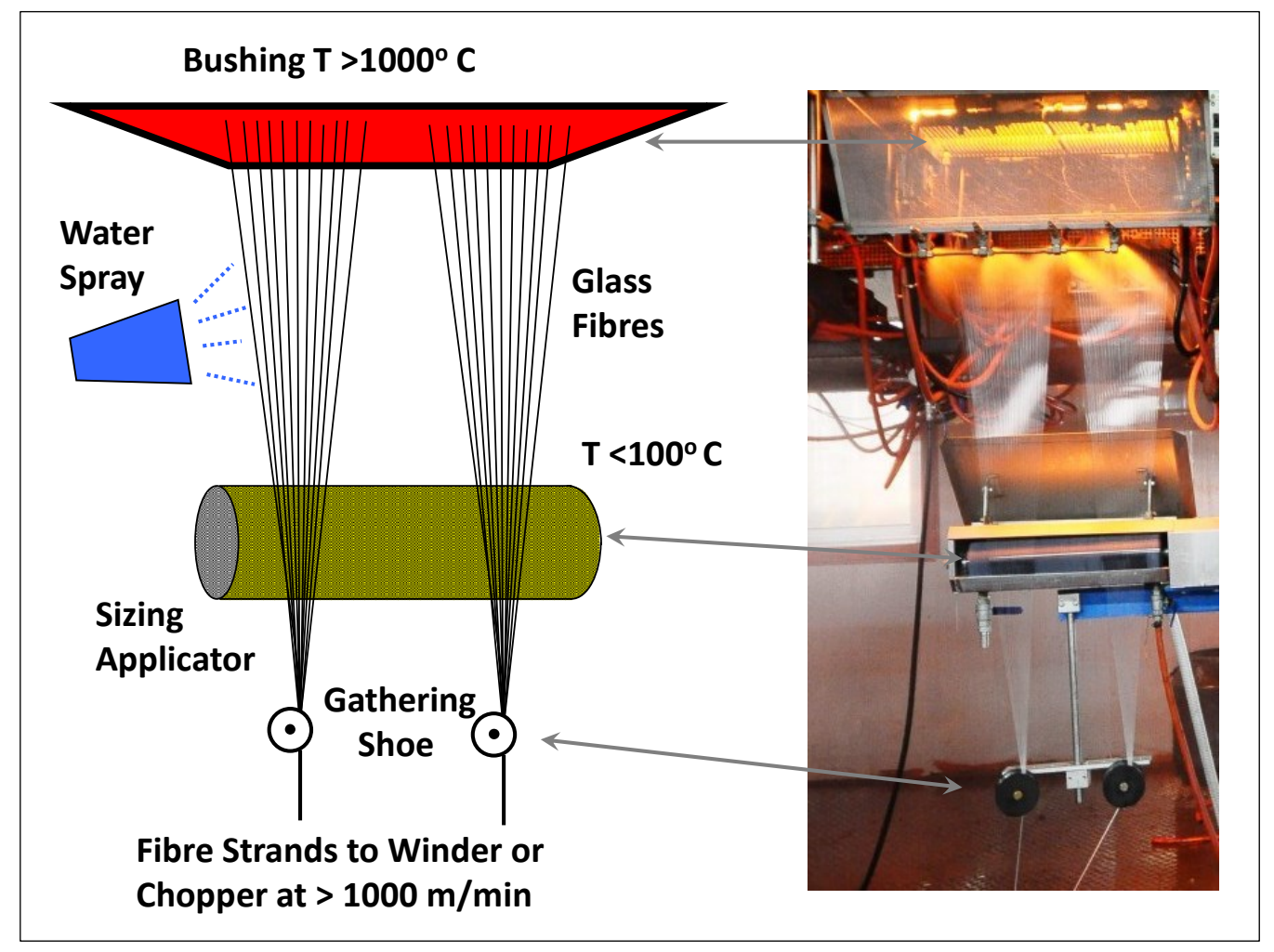

Figure 1. Schematic and picture of a glass fibre forming position

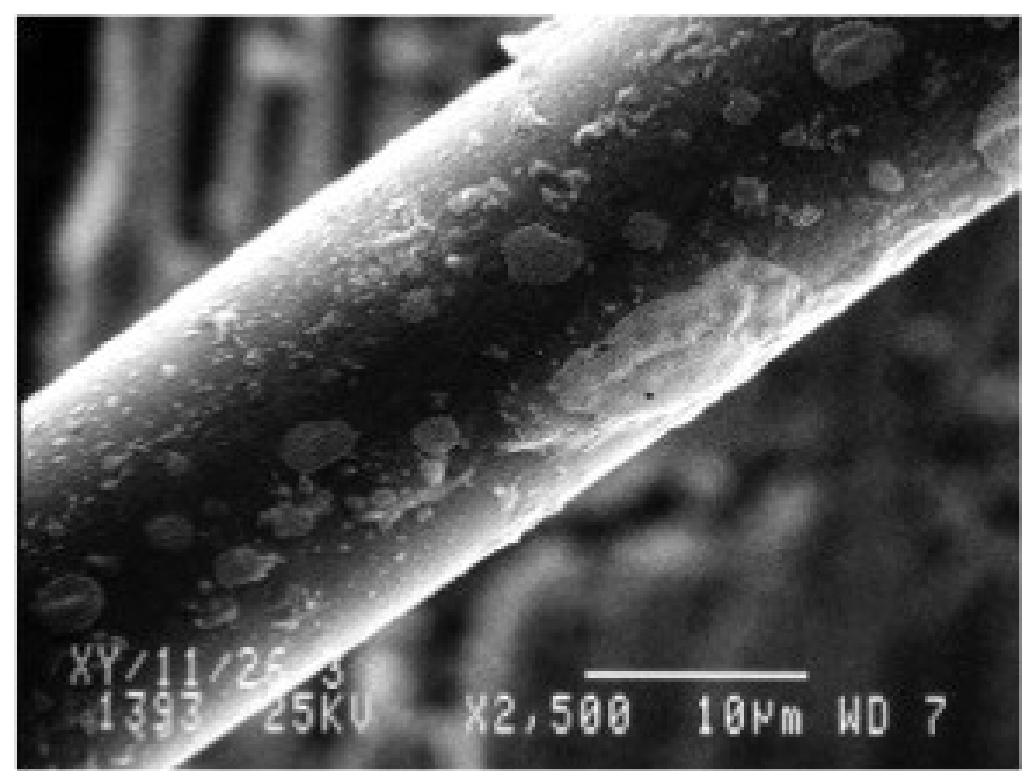

Figure 2. SEM image showing the non-uniform distribution of polymer sizing on a glass fibre surface 


\begin{tabular}{|c|c|c|}
\hline Method & Reference & Information Obtained, (Issues, Drawbacks) \\
\hline AFM & $\begin{array}{c}19, \\
47-54 \\
103\end{array}$ & $\begin{array}{l}\text { Surface topography and roughness, silane patches, } \\
\text { (sample preparation challenging, results are extremely } \\
\text { localised and may not be fully representative of overall } \\
\text { fibre, interface, composite performance) }\end{array}$ \\
\hline CA & $\begin{array}{l}4,11-14 \\
55-72 \\
75,76 \\
95,96\end{array}$ & $\begin{array}{l}\text { Surface energy, surface coating uniformity and thickness, } \\
\text { wettability, surface hydroxyl group concentration } \\
\text { (sample preparation and contamination issues, coverage } \\
\text { only semi-quantitative), fibre surface hydroxyl group } \\
\text { concentration (sample preparation, contamination issues) }\end{array}$ \\
\hline CSOM & 94 & $\begin{array}{l}\text { Sizing inhomogeneity on fibre and in composite } \\
\text { interphase (requires components to fluoresce) }\end{array}$ \\
\hline DMA & $4,30-38$ & $\begin{array}{l}\text { interphase formation in composites, sizing transition } \\
\text { temperature (results dependent on thickness of sizing } \\
\text { layer) }\end{array}$ \\
\hline EKA & $\begin{array}{l}5,11,12 \\
16,63,74 \\
\quad 97\end{array}$ & $\begin{array}{l}\text { Zeta potential of surface vs } \mathrm{pH} \text {, isoelectric point, } \\
\text { preferential adsorption of sizing components, } \\
\text { information on fibre-polymer interaction, silane } \\
\text { adsorption of fibre surface }\end{array}$ \\
\hline FTIR & $\begin{array}{c}14,80-87 \\
91,103\end{array}$ & $\begin{array}{l}\text { Adsorption and adhesion of sizing components to GF } \\
\text { surface, hydrolytic stability of silane layer (after hot water } \\
\text { extraction), sizing decomposition (thermal) }\end{array}$ \\
\hline IGC & $\begin{array}{c}77-79,92 \\
97\end{array}$ & $\begin{array}{l}\text { Analysis silane adsorption and structure on GF, surface } \\
\text { energy, surface heterogeneity (not reliable, too sensitive to } \\
\text { give unambiguous description of sizing layer) }\end{array}$ \\
\hline LOI & 9 & $\begin{array}{l}\text { Sizing content (averaged over about } 1 \text { m of fibre strand - } \\
\text { no local information at fibre level or distribution) }\end{array}$ \\
\hline PCGMS & 96 & Identification of sizing thermal degradation products \\
\hline SEM & $8,27,91,97$ & Sizing surface morphology, coverage \\
\hline SIMS & $\begin{array}{c}4,21-24 \\
96\end{array}$ & $\begin{array}{l}\text { Silane and Film Former (FF) component identification, } \\
\text { interphase formation in composites, reaction of silane } \\
\text { with FF (requires specific different atoms to be present in } \\
\text { silane and FF) degree of polymerisation of silane, } \\
\text { extraction of glass atoms by silane }\end{array}$ \\
\hline TGA & $\begin{array}{l}40-42 \\
44-46\end{array}$ & $\begin{array}{l}\text { Thermal stability, degradation of sizings (results may be } \\
\text { dependent on thickness of sizing layer) }\end{array}$ \\
\hline XPS & $\begin{array}{l}4,5,8,10 \\
11,15-19 \\
25-29 \\
91,92,95 \\
96,99,108\end{array}$ & $\begin{array}{l}\text { Glass surface composition (strongly affected by sample } \\
\text { prep, contamination), amount of sizing on surface } \\
\text { (only semi-quantitative), patchy silane and sizing } \\
\text { coverage, hydrolytic stability (of silane), preferential } \\
\text { adsorption of silanes (requires silica surface), sizing } \\
\text { uniformity and thickness (high level of scatter in results), } \\
\text { identification of silane in sizing (with unique atoms, e.g. } N \\
\text { or } S \text { ), sizing solubility, chemical nature of sizing }\end{array}$ \\
\hline
\end{tabular}

Table 1 Analysis methods used on sizing on fibres or on solvent extracted fibres 


\begin{tabular}{|c|c|c|}
\hline Method & Reference & Information Obtained, (Issues, Drawbacks) \\
\hline $\begin{array}{l}\text { DSC, } \\
\text { DMA }\end{array}$ & $4,43,109$ & $\begin{array}{l}\text { Transition temperature of sizing and effect on Tg of } \\
\text { composite matrix, interphase formation in } \\
\text { composites. Modulus of cast films of FF }\end{array}$ \\
\hline NMR & $4,43,93,108$ & identification of extracted film former components \\
\hline FTIR & $\begin{array}{c}4,89,91,93 \\
95-99,105- \\
107,109\end{array}$ & $\begin{array}{l}\text { Miscibility of silane and FF, chemical identification of } \\
\text { sizing (only generic chemical types identified, small } \\
\text { amounts of silane not identified, difficult to distinguish } \\
\text { unambiguously between fibres), competitive } \\
\text { adsorption silane vs lubricant }\end{array}$ \\
\hline GPC & 109 & Molecular weight of FF components \\
\hline HPLC & 99 & Molecular weight of extracted sizing components \\
\hline MDE & 39 & Swelling and dissolution rates of sizing \\
\hline NIR & 90 & Chemical reaction between silane and FF \\
\hline NMR & $4,43,93,108$ & Identification of extracted sizing components \\
\hline PCS & 109 & FF particle size distribution \\
\hline TGA-MS & 105,107 & Identification of FF thermal degradation products \\
\hline UVS & 109 & clarity (yellowing) of the sized fibres. \\
\hline
\end{tabular}

Table 2 Analysis methods used on bulk sizing or sizing solvent extracts 